\title{
The Apicoplast: A Review of the Derived Plastid of Apicomplexan Parasites
}

\author{
Ross F. Waller ${ }^{1}$ and Geoffrey I. McFadden ${ }^{2, *}$ \\ ${ }^{1}$ Botany, University of British Columbia, 3529-6270 \\ University Boulevard, Vancouver, BC, V6T 1Z4, Canada \\ ${ }^{2}$ Plant Cell Biology Research Centre, Botany, University \\ of Melbourne, 3010, Australia
}

\begin{abstract}
The apicoplast is a plastid organelle, homologous to chloroplasts of plants, that is found in apicomplexan parasites such as the causative agents of Malaria Plasmodium spp. It occurs throughout the Apicomplexa and is an ancient feature of this group acquired by the process of endosymbiosis. Like plant chloroplasts, apicoplasts are semi-autonomous with their own genome and expression machinery. In addition, apicoplasts import numerous proteins encoded by nuclear genes. These nuclear genes largely derive from the endosymbiont through a process of intracellular gene relocation. The exact role of a plastid in parasites is uncertain but early clues indicate synthesis of lipids, heme and isoprenoids as possibilities. The various metabolic processes of the apicoplast are potentially excellent targets for drug therapy.
\end{abstract}

\section{Introduction}

The apicomplexan plastid was a discovery waiting to be made. With hindsight it seems incredible that such an organelle could have so long concealed its identity in cells that have received as much scientific attention as Plasmodium. In fact these plastids, referred to as apicoplasts in apicomplexan parasites, had been observed but not recognized as plastids. As early as the 1960s electron microscopists had described the ultrastructure of a mysterious multi-membrane-bound organelle from Plasmodium spp. as well as from all other major groups of apicomplexan parasites (see McFadden et al., 1997 for review). Moreover, circular organellar DNAs, that we now know belong to the apicoplast, were observed, measured, and cruciform secondary structures noted (formed by inverted repeats of rRNA genes, a classic feature of plastid genomes) (Kilejian, 1975; Dore et al., 1983; Borst et al., 1984). We were even aware of the sensitivity of Plasmodium to a range of plastidtargeting antibiotics (though these were assumed to target the parasite mitochondrion). However, none of these observations could have reasonably inspired anyone to claim that Plasmodium is descended from photosynthetic stock and that it still maintains a plastid organelle.

It required the depth of genomic data to awaken us to the strange possibility of Plasmodium being a highly derived alga. lain Wilson's group paved the

*For correspondence. Email g.mcfadden@botany.unimelb.edu.au. way to apicoplast discovery with studies of extrachromosomal DNAs recovered from isopycnic density gradient fractionation of total Plasmodium DNA. This group recovered two DNA forms; one a $6 \mathrm{~kb}$ tandemly repeated element that was later identified as the mitochondrial genome, and a second, $35 \mathrm{~kb}$ circle that was supposed to represent the DNA circles previously observed by microscopists (Wilson et al., 1996b; Wilson and Williamson, 1997). This molecule was also thought to be mitochondrial DNA, and early sequence data of eubacterial-like rRNA genes supported this organellar conclusion. However, as the sequencing effort continued a new conclusion, that was originally embraced with some awkwardness ("Have malaria parasites three genomes?", Wilson et al., 1991), began to emerge. Gradually, evermore convincing character traits of a plastid genome were uncovered, and strong parallels with plastid genomes from non-photosynthetic plants (Epifagus virginiana) and algae (Astasia longa) became clear. These studies culminated with the completion of the $35 \mathrm{~kb}$ sequence, by which time the chromosome architecture, gene content and gene arrangement were undeniably plastid-like (Wilson et al., 1996b; McFadden and Waller, 1997; Wilson and Williamson, 1997; Gleeson, 2000).

Final proof of a plastid organelle awaited defining the location of this plastid-like DNA. Maternal inheritance of this DNA circle strongly argued that it was located in a non-nuclear organelle (Creasey et al., 1994). A lack of co-purification with the mitochondrion (converse to the $6 \mathrm{~kb}$ extra-chromosomal DNA) told us that this organelle was separate to the mitochondrion (Wilson et al., 1992). Therefore a relict plastid seemed most likely. Suddenly plastid spotting in the old ultrastructural literature became a favored pastime of many, and the mysterious multi-membrane organelles quickly became the 'odds-on bet'. In situ hybridization experiments in Toxoplasma gondii using probes complementary to the plastid genome or its gene transcripts offered the final nail in the coffin by defining the locality of these molecules as a multi-membrane-bound compartment distinct from the mitochondrion or other organelles (McFadden et al., 1996; Köhler et al., 1997).

Genomic data had provided the first hint of a plastid in Apicomplexa, and also provided the tools for its identification at the cell level. Two immediate questions were raised by this discovery. (1) What is the origin of the apicoplast? (2) What is the function of the apicoplast in parasites? Again genomic data provided the major springboard for tackling these questions. Addressing the first question, phlylogeneticists have continuously poured over apicoplast molecular data for hints of the source of this plastid ever since the Wilson group's first partial sequences of the $35 \mathrm{~kb}$ circular DNA were produced. These studies have matured substantially as the body 


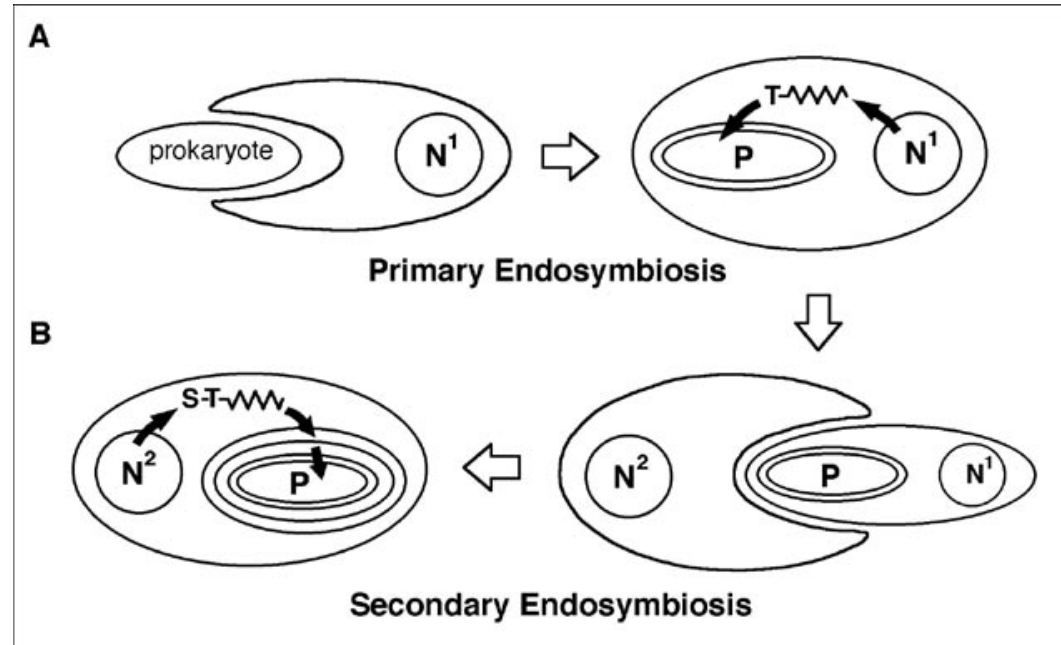

Figure 1. Plastid origins and protein targeting. (A) Primary endosymbiosis describes the uptake of a prokaryote by a eukaryote. Plastids derived by primary endosymbiosis are surrounded by two membranes and targeting of nucleus-encoded gene products to the endosymbiont is affected by an $\mathrm{N}$-terminal transit peptide (T). (B) Secondary endosymbiotic plastid origin involves a heterotrophic eukaryote phagocytosing a photosynthetic eukaryote possessing a primary endosymbiont. The secondary endosymbiont's cytoplasm and nucleus $\left(\mathrm{N}^{1}\right)$ are typically lost and the resulting plastid is surrounded by four membranes. Sometimes one of the two outer membranes is lost at this point, resulting in a total of three. Targeting of nucleus-encoded $\left(\mathrm{N}^{2}\right)$ gene products to secondary plastids requires a signal peptide $(\mathrm{S})$ to mediate protein passage across the outer membrane followed by a transit peptide ( $\mathrm{T}$ ) for import across the inner membranes.

of genomic data has expanded from parasites and other protists alike and their somewhat alarming findings will be discussed below. The second question - apicoplast function - has also provided an interesting journey. The sequencing of the apicoplast genome promised to offer insights into apicoplast metabolism, but instead revealed an extremely streamlined genome principally dedicated to its own expression plus that of a small handful of unidentified open reading frames. Direct biochemical or proteomic studies of the apicoplast have been obstructed by the lack of effective apicoplast purification techniques. So again, genomics have been called upon, this time to paint a picture of apicoplast metabolism from nucleusencoded genes whose products are targeted to the apicoplast. Through the characterization of the apicoplasttargeting signals in nucleus-encoded genes an evergrowing list of putative apicoplast genes in the nucleus is being assembled. This list enables a 'virtual tour' of apicoplast metabolism from genome data. To date this has provided our greatest insights into apicoplast function. Furthermore, these studies have lead directly to the identification of novel anti-malarials. This is undoubtedly the most exciting aspect of apicoplast research because the apicoplast's plant-like heritage offers a broad range of unique targets for chemotherapeutics. The completion of the Plasmodium genome potentially offers the identification of the complete protein content of the apicoplast, from which an extensive picture of apicoplast metabolism can be made.

Few areas of malarial research can boast gaining so much from genomic studies. This review presents a summary of our current understanding of the apicoplast based both on genomic and other data.

\section{Origin of the Apicoplast}

All plastids are derived from a prokaryote that entered into an endosymbiotic partnership with a eukaryotic host cell
(Cavalier-Smith, 1982). In fact, it is widely believed that all modern plastids are derived from a single symbiotic event where the endosymbiont was a cyanobacterial-like organism (Delwiche and Palmer, 1997). The apicoplast is, without doubt, a bona fide member of this family of organelles because of its plastid-type genome. However, there are two main categories of plastids - primary plastids and secondary (or complex) plastids. Primary plastids are the products of a symbiosis between a prokaryote and a eukaryote (see Figure 1A). These plastids are surrounded by two membranes and are represented in three major groups; plants and green algae, red algae, and an unusual algal group called glaucophytes (Delwiche, 1999). Secondary plastids are more complicated. These are derived from symbioses between two eukaryotes where a primary plastidcontaining eukaryote is engulfed by a second eukaryote (Figure 1B). With time this engulfed eukaryotic is stripped of its now redundant features, and many of its genes are transferred to the host nucleus, until essentially only a plastid remains (exceptions do exist where a miniature nucleus and some cytosol persist). However, this plastid remains bound by either one or two extra membranes derived from its former host cell's plasma membrane and/or the food vacuole of its new host (Figure 1B). These extra membranes are diagnostic of secondary plastids that are found in the following diverse algal groups; dinoflagellates, heterokont algae (including kelps and other brown algae), haptophytes, cryptomonads, chlorarachniophytes and euglenoids (Delwiche, 1999). Apicoplasts are also surrounded by extra membranes (see following section for discussion of how many) which is evidence for them being secondary plastids. The route of protein trafficking to plastids is also strongly discriminating between primary and secondary plastids and in apicomplexans provides a compelling case for the apicoplast being a secondary plastid (protein trafficking is discussed in detail in a following section). 
The identification of the apicoplast as a secondary plastid tells us the method by which the progenitor of apicomplexans acquired a plastid, but key questions remains unanswered. What type of plastid-containing organism (alga) was the endosymbiont? Was this plastid acquired before apicomplexans diverged from related protists or after? If the answer is before, do other groups share this plastid? If the answer is after, have different apicomplexans independently acquired their own plastids? It is important to note that the sister taxon to the Apicomplexa is the dinoflagellate algae, and the nearest relatives of this pair are the ciliates. This grouping is well supported by both molecular and ultrastructural data, and is referred to as the Alveolata (Vivier and Desportes, 1990; Baldauf et al., 2000). Most dinoflagellates possess a secondary plastid (containing peridinin pigment) (Delwiche, 1999) which has lead to the enticing hypothesis that apicomplexans and dinoflagellates share a common plastid. However, this scenario is confounded by numerous of the dinoflagellates having acquired further secondary plastids independently (Delwiche, 1999), raising the possibility that either the dinoflagellates, or apicomplexans or both may have acquired their plastids separately. Ciliates, on the other hand, typically lack a plastid.

Traditional features that help define plastid lineages such as pigments (chlorophyll $b$ versus chlorophyll $c$ ) and genes associated with photosynthesis (Rubisco forms) are absent in the non-photosynthetic apicoplast, so other molecular markers must be sought for the task of tracing apicoplast history. Genes encoded on the plastid genome are one obvious class of useful markers of plastid lineage. Nucleus-encoded genes, however, can also be very useful markers particularly as they are independent of any evolutionary constraints placed on plastid-encoded genes such as strong AT content or codon usage biases. Thus, genes that originated with the plastid (either from the plastid DNA or, in the case of secondary plastids, the endosymbiont's nucleus) but have relocated to the nucleus can also serve as useful markers of plastid heritage. Most of these genes traffic their products back to the plastid, although, some may come to fulfill functions in the host cytosol. In either case, such genes can offer phylogenetic information of the endosymbiont from which they derive. Genes that derive from the host cell rather than the endosymbiont, but become associated with plastid function, can also be useful markers. An example is a host gene whose protein product has become targeted to the plastid to fulfill an organellar role. If its role is stable, it can continue to be a useful marker for all plastid descendants subsequent to its adoption. Attempts to identify the source and history of the apicoplast have utilized all of these different classes of molecular markers.

\section{Plastid-Encoded Markers}

Apicoplast-encoded sequences have received the greatest attention in attempts to identify apicoplast affinities with other plastids. Early studies, conducted as the first apicoplast sequences were becoming available, were encumbered by poor taxa representation in the data sets and will not be discussed here (see Jeffries and Johnson, 1996, for a comprehensive review). With the completion of several plastid genome sequences, including two from the Apicomplexa (Plasmodium falciparum and Toxoplasma gondii) (Wilson et al., 1996b; Köhler et al., 1997) and partial genome sequences from a number of others (Denny et al., 1998), these studies have become much more potent.

\section{Apicomplexa Share a Common Plastid}

Plastid sequence data strongly support that all apicoplasts share a common origin. Lang-Unnasch and co-workers constructed phylogenetic trees from apicoplast-encoded rRNA genes representing much of the diversity of the Apicomplexa (Lang-Unnasch et al., 1998). These tree topologies basically match those derived from nuclear sequences suggesting that the apicoplast has been co-evolving with the host cell throughout apicomplexan diversification. Further evidence for all apicoplasts sharing a common origin comes from the striking similarities of apicoplast genomes. Plasmodium falciparum and Toxoplasma gondii, representing haemosporins and coccidians respectively, have near identical plastid genomes in terms of gene content and order (Wilson et al. 1996b; Köhler et al., 1997; http://www.sas.upenn.edu/ jkissing/toxomap.html). Denny et al. (1999) have added further partial genome sequences from another coccidian, Eimeria tenella, and the piroplasm Theileria annulata. These sequences also show a remarkable level of genome conservation. This uniformity of the genome not only supports a common origin of the apicoplast, but shows that its genome had reached a stable evolutionary state prior to apicomplexan diversification. This suggests that the acquisition of this secondary plastid may predate the divergence of the Apicomplexa from related protists.

This conclusion implies that all apicomplexa should contain a plastid, unless members have subsequently lost this organelle. Indeed, molecular and/or ultrastructural data indicates that an apicoplast is present in all major apicomplexan groups (McFadden et al., 1997; Lang-Unnasch et al., 1998). One possible exception is Cryptosporidium for which extensive searching for evidence of an apicoplast has failed to find any (Zhu et al., 2000a). This member may, therefore, have lost its apicoplast since its divergence from other apicomplexa.

\section{Apicoplast-Encoded Genes Support a Non-Green Origin?}

If the apicoplast is monophyletic (of single origin) and possibly more ancient than apicomplexan diversification, then this raises the possibility that it may be the homologue of other algal secondary plastids. Again the spot-light falls upon the Apicomplexa's sister taxon the dinoflagellates. For a long time no plastid DNA could be recovered from dinoflagellates, preventing any comparison of heritage with the apicoplast. In 1999 two groups broke this impasse. However, what they found was highly divergent genes each arranged individually on DNA mini-circles (Takishita and Uchida, 1999; Zhang et al., 1999; 2001). This radical reorganization of their plastid genomes is perhaps consistent with other aberrant features of dinoflagellate genetic organization (such as the nucleus). Again, comparisons to the apicoplast were frustrated. 


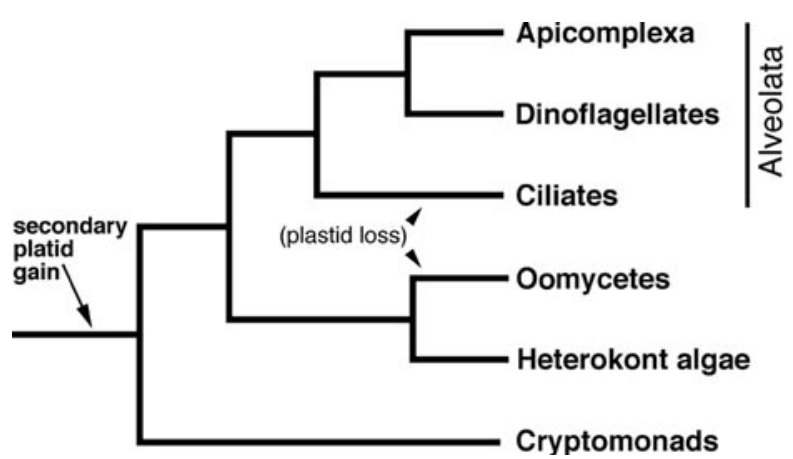

Figure 2. Hypothesised evolution of protists sharing a common ancient secondary plastid. Apicomplexans, dinoflagellates and ciliates form a well supported grouping known as the Alveolata. GAPDH phylogenies of Fast et al., (2001) support that apicomplexans, dinoflagellates, heterokont algae and cryptomonad algae share a secondary plastid derived from a single endosymbiotic event (arrow). This implies that ciliates and oomyctes (well established sisters to the heterokont algae) are derived from plastid containing ancestors that have lost their plastid (arrowheads).

Earlier studies argued for a link between apicoplasts and green (chlorophyll $b$-containing) plastids. rRNA and RNA Polymerase gene sequences often grouped the apicoplast with euglenoid algae (these contain green secondary plastids) (Howe, 1992; Gardner et al., 1994; Egea and Lang-Unnasch, 1995), while TufA gene sequences suggested a direct link with green algae (implying that the apicoplast is derived from an green algal endosymbiont acquired independently from dinoflagellate plastids) (Köhler et al., 1997). However, limited taxon sampling, poor statistical support for these alliances, and the artifactual phenomenon of divergent sequences (often with strong AT biases) attracting in phylogenies, all cast a shadow over these conclusions (Blanchard and Hicks, 1999).

Analyses of plastid gene loss and rearrangement on plastid genomes argues more convincingly for apicoplast affinities with non-green plastids. Plastid ribosomal protein genes are organized into two gene clusters in cyanobacteria, plants and green algae, whereas non-green plastids have combined these into a single "super operon". Apicoplasts share this "super operon" gene organization (Wilson et al., 1996b; McFadden et al., 1997). Furthermore, while gene loss from the plastid genome has occurred in all plastids since their endosymbiotic origin, the apicoplast retains more of these ribosomal protein genes in common with non-green plastids compared to the green counter-parts (McFadden et al., 1997; Blanchard and Hicks, 1999).

\section{Nucleus-Encoded Markers}

Markers for the apicoplast that are encoded in the nucleus didn't become available for some time after the discovery of this organelle. The first to be analyzed were ribosomal protein genes rps 9 and $r p / 28$, and fatty acid biosynthesis gene $f a b H$, all of which encode proteins that are trafficked into the apicoplast (Waller et al., 1998). Phylogenies with these sequences supported their plastid origin but again limited taxon sampling prevented any meaningful resolution of the order amongst the plastids (Waller et al., 1998). Nevertheless, these sequences offered a ray of hope given that many more (most probably hundreds) of other apicoplast genes promised to be found in the nuclear genome. This promise has indeed been fulfilled and this resource will undoubtedly provide the greatest power for resolving this issue of apicoplast origin. Amongst these genes, Sato et al, (2000) have even apparently identified genes that derive from the apicoplast, but now fulfill cytoplasmic functions. Useful phylogenetic markers still await identification from these genes. However, one group (Fast et al., 2001) have made a promising break through from an unexpected quarter.

Fast et al. (2001) noted that plastid-targeted GAPDH (glyceraldehyde-3-phosphate dehydrogenase) in dinoflagellates was distinct from that of plants, green aglae and red algae. The later all possess a cyanobacteriumtype version of this enzyme that is nucleus-encoded and plastid-targeted (this is in addition to a eukaryotictype cytosolic version of this enzyme that all eukaryotes possess). Dinoflagellates, on the other hand, target a eukaryotic version of this enzyme to their plastids (Fagan et al., 1998). This suggests that a gene duplication of the cytosolic form has lead to one copy displacing the cyanobacterial version at some point in dinoflagellate evolution (endosymbiotic gene displacement is not uncommon in plastids) (Liaud et al., 1997; Fagan et al., 1998). Fast et al. (2001) recognized that this dichotomy amongst plastids offered an excellent opportunity to test the relationship of apicoplasts to dinoflagellate plastids. They sequenced several plastid GAPDH genes including one from Toxoplasma gondii, and several from non-green algae, and revealed that apicoplasts possess a eukaryotic GAPDH similar to dinoflagellates. Moreover, other non-green algae (heterokont algae and cryptomonads) also possess this eukaryotic version, and in GAPDH phylogenies these group tightly together with the Apicomplexa and dinoflagellates. Interestingly, the cytosolic version of GAPDH from all of these taxa (with the exception of cryptomonads) also group together and form a sister group to the plastid targeted form. This is consistent with a gene duplication event prior to the divergence of these groups.

This stunning result has the profound consequence that the apicoplast is derived from an extremely ancient secondary endosymbiotic event, and is shared not only by dinoflagellates, but also heterokont algae, and probably cryptomonads (notable plastid losses are also predicted, see Figure 2). The original endosymbiont was almost certainly a red alga based on strong pigmentation and plastid gene data that links the plastids of heterokont algae and cryptomonads with those of red algae (Delwiche, 1999). This result also lends support to heterokonts being the sister to the Alveolata, a notion with increasing support (Baldauf et al., 2000; Van de Peer et al., 2000). Further analysis of the Plasmodium genome, in conjunction with expanding genome data from other protists, will offer many more opportunities to test the hypothesis of Fast et al. (2001). However for now, we are enjoying the clearest picture that we have had yet of the apicoplast, as a formerly photosynthetic, ancient secondary plastid that has played a major role in the evolution of protistan life. 


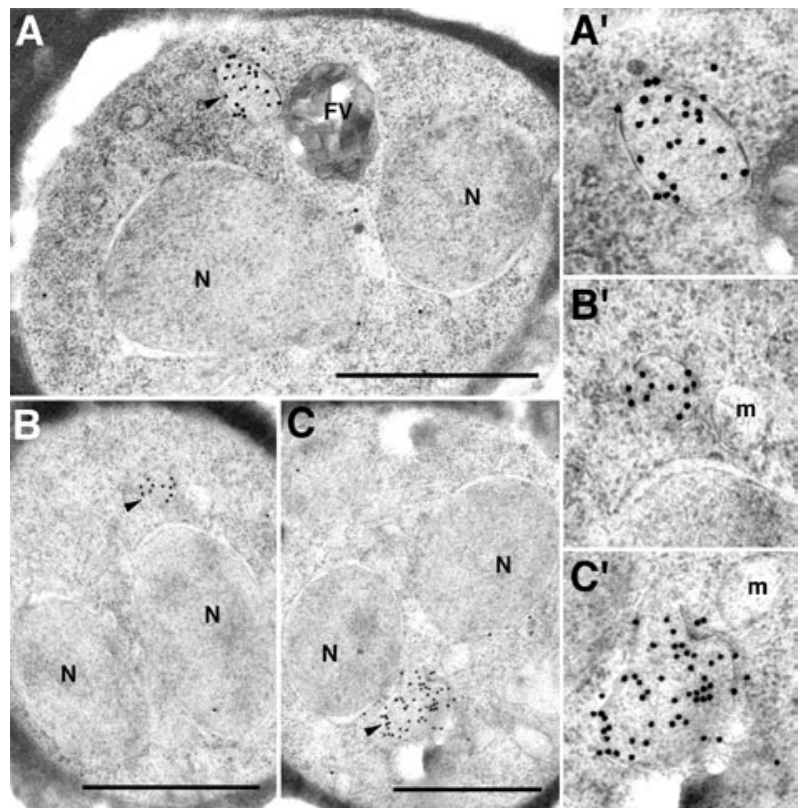

Figure 3. Apicoplast ultrastructure in Plasmodium falciparum. Parasites represent schizont stages containing multiple nuclei. GFP is targeted to the apicoplast via a transgene (encoding $\mathrm{ACP}_{\text {presequence-GFP, see }}$ 'Protein targeting to apicoplasts' section) and is visualized by immunogold detection of GFP. Mitochondrion profiles are seen in close proximity to apicoplasts in B' and C'. Sections are made from cryopreserved cells. $\mathrm{N}$, nucleus; FV, food vacuole; arrowhead, apicoplast; $\mathrm{m}$, mitochondrion. Scale bar $=1 \mu \mathrm{m}$.

\section{Apicoplast Morphology and Division}

Apicoplast ultrastructural studies enjoy the unusual distinction that much of this work was done decades before the discovery of this organelle's true identity. These early apicoplast studies span much of the diversity of the Apicomplexa and, because no one knew they were observing a plastid, the apicoplast acquired many different labels (see McFadden et al., 1997 for summary of early microscopy). Amongst Plasmodium spp., "spherical body", "double walled organelle" and simply "vacuole" were used. These studies, in conjunction with more recent work, still contribute substantially to our understanding of apicoplast structure.

\section{Number of Surrounding Membranes}

The apicoplast is a multi-membrane-bound compartment that can vary in size and shape during the cell cycle. The number of membranes surrounding apicoplasts has been a matter of some debate due to the required exceptional levels of membrane preservation for this to be accurately defined. Consequently, in the past the apicoplast was often simply described as a multi-membrane compartment without any commitment to an actual membrane number. Some exceptions, however, do exist, and Toxoplasma gondii is the most noteworthy having dazzled electron microscopists for years with superb ultrastructural preservation. In this case it is clear that four membranes surround the apicoplast (Dubremetz, 1995; Köhler et al., 1997). Other apicomplexa have also lent themselves to answering this question of membrane number. Another coccidian, Hepatozoon domerguei, is identified as having
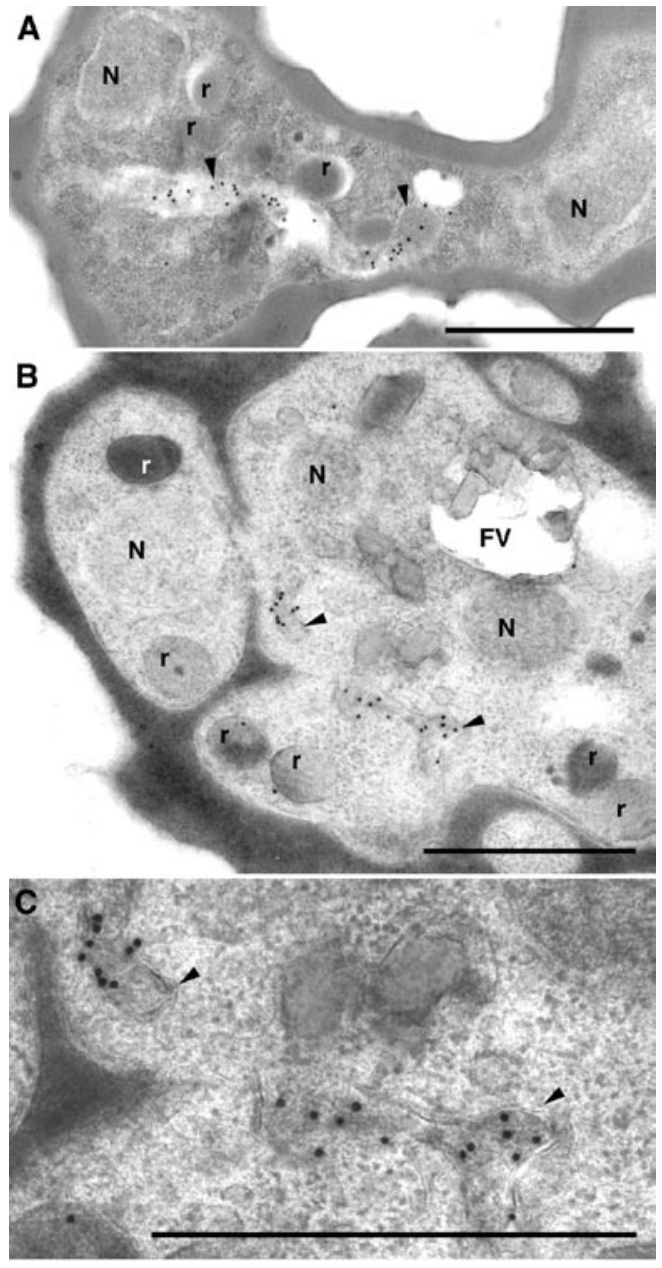

Figure 4. Apicoplast ultrastructure in late schizont-stage Plasmodium falciparum parasites expressing $A C P$ presequence-GFP (see Figure 3 ). Immuno-gold detection of GFP labels the apicoplast. (A) Multi-nucleate stage with a long apicoplast profile. (B and $C$ ) Segregating parasite with profiles of branched forms of the apicoplast. (C) Enlarged branched apicoplast showing multiple membranes surrounding the apicoplast. Panel A represents standard chemical fixation whilst panels $B$ and $C$ represent cyropreservation. Arrowheads, apicoplast; N, nucleus; FV, food vacuole; $r$, rhoptry. Scale bar $=1 \mu \mathrm{m}$.

four membranes around its apicoplast (Vivier et al., 1972), as does Coelotropha durchoni (Viviere and Hennere, 1965), a further coccidian, and the gregarine Selenidiidae pendula (Schrevel, 1971). More recently, a study of the haemosporin, Garnia gonandati, clearly identifies a four membrane apicoplast in this close relative of Plasmodium spp. (Diniz et al., 2000).

From this broad representation of apicomplexa it is probable that most, if not all, apicoplasts will be bounded by four membranes. However, one group (Hopkins et al., 1999) have argued that Plasmodium spp. are exceptions, having three membranes around their apicoplasts. Hopkins et al. (1999) have made a detailed microscopic study, including the use of serial sections, of apicoplasts from $P$. falciparum. $P$. falciparum in notorious for poor ultrastructural preservation by chemical fixation, and this study also is confounded by wavy and folded membrane profiles that are often dilated, discontinuous and merge 
into one another. Comparisons with smoother membrane profiles from cryopreserved material (Figures 3 and 4) suggest that this waviness is likely the result of chemical fixation artifacts. Despite recognizing that different apicoplast profiles showed three, four and five bounding membranes, Hopkins and co-workers are convinced that three is the true number for $P$. falciparum. It is interesting to note that if the apicoplast has a common ancestry with dinoflagellate, heterokont and cryptomonad plastids (see previous section), then the loss (or gain) of plastid membranes has occurred before in this plastid lineage. Heterokont and cryptomonad plastids are surrounded by four membranes (most likely the ancestral state) while this plastid in dinoflagellates has only three (Delwiche, 1999). This suggests that one membrane has been lost during dinoflagellate evolution, and an equivalent event could have happened much more recently in Plasmodium evolution (since the two haemosporins, Garnia and Plasmodium, diverged). This membrane loss is not evident, however, by protein-targeting to apicoplasts, either in the route or interchangeability of proteintargeting motifs between $P$. falciparum and Toxoplasma gondii (discussed in the following section). Furthermore, one image from a $P$. falciparum gametocyte (for which ultrastructural preservation is typically better than for the asexual blood stages) shows a likely apicoplast clearly with four surrounding membranes (McFadden and Roos, 1999). Therefore, we await further confirmation of membrane number from Plasmodium spp..

\section{Apicoplast Contents}

Throughout the apicomplexa apicoplast contents are typically homogenous with a finely granular and sometimes fibrous texture (Figures 3 and 4, and McFadden et al., 1997 for references). These fine granules are consistent in size with plastid-type $70 \mathrm{~S}$ ribosomes (McFadden et al., 1996; Hopkins et al., 1999). Occasionally, some differentiation of the lumenal contents has been noted where more darkly staining regions in electron micrographs co-occur with pools of rRNAs (McFadden et al., 1996; McFadden et al., 1997). The fibrous nature of the apicoplast lumen has been suggested to represent the DNA content of these organelles. Apicoplast genome copy number is another contentious issue, with earlier estimates of average apicoplast content based on Southern blot analysis suggesting extremely low counts of six for Toxoplasma gondii and only one for Plasmodium falciparum (Fichera and Roos, 1997; Köhler et al., 1997). More recently, measurements have been made on individual cells using video-intensified microscope photon counting, and less extreme values were determined with approximately 25 copies for $T$. gondii and 15 for $P$. falciparum (Matsuzaki et al., 2001). Interestingly, in T. gondii, the apicoplast DNA content showed significant variation, with up to 80 copies evident in some apicoplasts (Matsuzaki et al., 2001). Apicoplast DNA has been observed as a discrete nucleoid concentrated in a small portion of the $T$. gondii apicoplast by fluorescence microscopy (Striepen et al., 2000). At the electron microscope level, a similar result is seen by immuno-detection of DNA, with most staining in concentrated foci (Matsuzaki et al., 2001). The latter authors, however, suggest that this is artifactual based on seeing more homogenous DNA staining in their fluorescent studies. Yet in the absence of an independent apicoplast stain for these fluorescent images, they may have overlooked any segregation of DNA staining within apicoplasts.

The Hopkins study (Hopkins et al., 1999) of Plasmodium falciparum apicoplasts report extra membranous structures both inside the apicoplast lumen as well as on the outside surfaces. These internal structures are unique to Plasmodium and consist of infolding waves and whorls of membrane that are apparently continuous with the bounding plastid membranes (the nature of the external structures is less clear). Hopkins et al. (1999) observe these structures to become more elaborate as the parasites develop right through to schizonts and early merozoites. It is suggested that these membranes may indicate mass lipid transport out of the apicoplast to the rest of the parasite (Hopkins et al., 1999). However, at this stage we cannot rule out that these structures represent artifacts of chemical fixation, and we note that we have not observed any equivalent structures in cryopreserved material representing late trophozoites and schizonts (Figures 3 and 4).

\section{Apicoplast Lifecycle In Asexually Reproducing Plasmodium falciparum}

In Plasmodium falciparum each parasite contains only one apicoplast. This is clearly evident from studies of live parasites using targeted GFP as a marker for the plastid (Figures 5 and 6A) (Waller et al., 2000). Apicoplast-targeted GFP has also provided an unprecedented opportunity to observe this structure throughout the lifecycle of $P$. falciparum with observations of many hundreds of live cells. These studies reveal a continuous, intimate association of the apicoplast with the mitochondrion (Figure 6A) (Waller et al., 2000). This union has also been observed at the electron microscope level (Figure 3B'-C') (Hopkins et al., 1999), and is even more pronounced in some of the non-human malaria parasites where the apicoplast sits within a deep invagination of the mitochondrion (Aikawa, 1966; Aikawa and Jordan, 1968; Aikawa, 1971; Hopkins et al., 1999). The significance of this association is unclear.

At the beginning of the asexual lifecycle of $P$. falciparum, when it has newly infected an erythrocyte, the apicoplast is rod shaped and slightly curved, perhaps due to being appressed against the plasma membrane in these tiny cells (Figure $5 \mathrm{~A}$ ). As this early ring stage develops the apicoplast rounds up into a small spherical structure (Figure 5B). This spherical conformation persists for most of the asexual life cycle, with only a gradual increase in apicoplast size taking place as the trophozoite grows (Figure 5C). The mitochondrion, on the other hand, elongates and elaborates early on in parasite development (Divo et al., 1985), although it continues to remain in contact with the apicoplast (Figures 3B'-C', and $6 \mathrm{~A}$ ). When the parasite has enlarged to fill most of the erythrocyte the sequence of cell division must commence. It is now that we see a dramatic change in apicoplast morphology. 


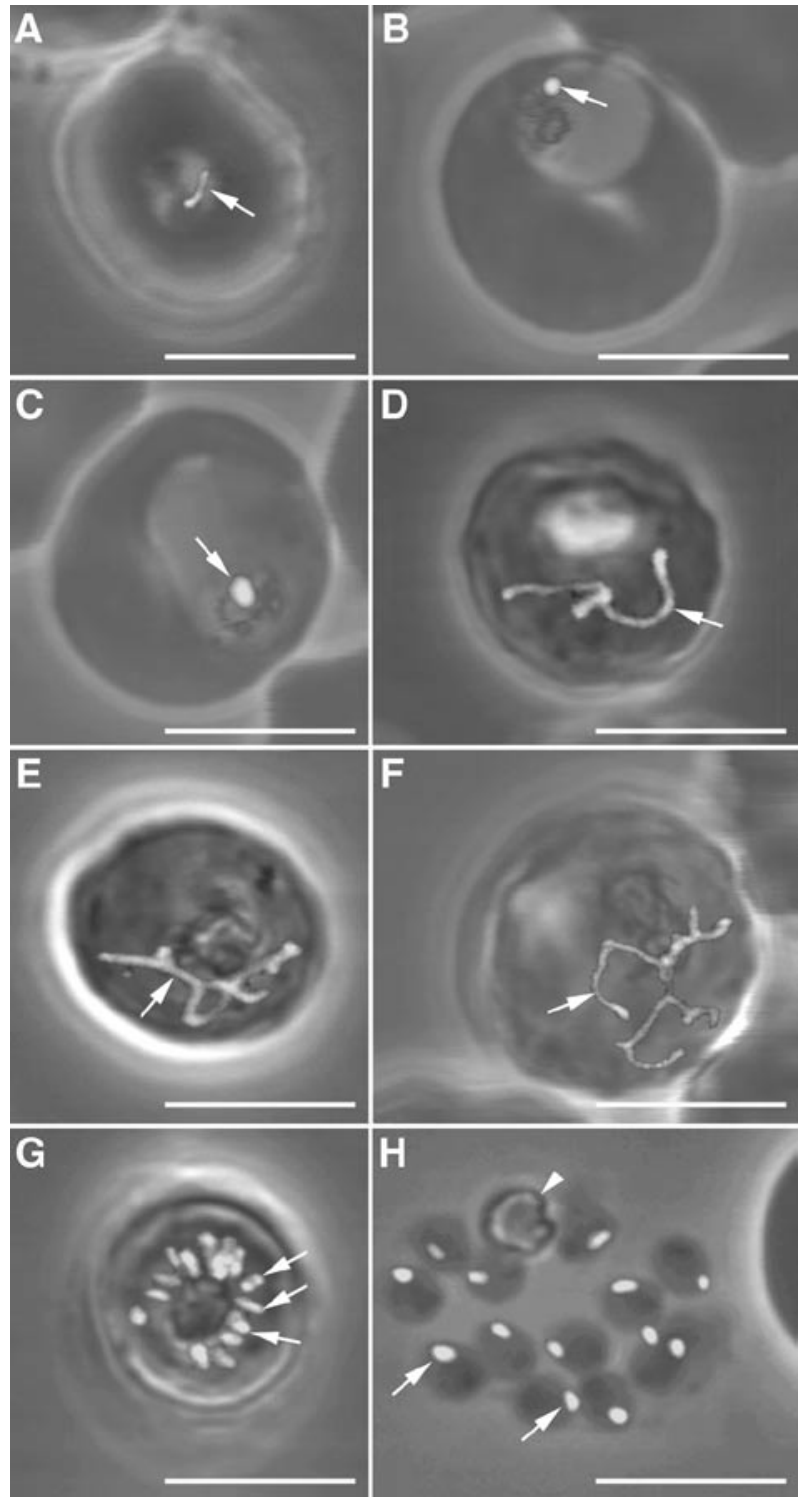

Figure 5. Plasmodium falciparum apicoplast morphology in live cells throughout the asexual lifecycle of blood stage parasites expressing apicoplast-targeted GFP (arrows). Stages represent ring form (A), small trophozoite (B), large trophozoite (C), three stages of early schizonts $(D-F)$, late schizont $(G)$ and recently released merozoites (remnant food vacuole is seen amongst the merozoites, arrowhead) $(H)$. Single apicoplasts enlarge slowly, elongate to branched forms during schizogony and then divide and segregate prior to merozoite egression. These stages were seen for all transfectants with apicoplast-targeted GFP. Panels A$\mathrm{E}$ and $\mathrm{G}-\mathrm{H}$ represent $A C P_{\text {presequence }}$-GFP expressing parasites and panel $\mathrm{F}$ represents a $\mathrm{FabH}_{\text {presequence }}$-GFP expressing parasite. Scale bars $=5 u \mathrm{~m}$.

\section{Apicoplast Division}

During the late trophozoite/early schizont stage the apicoplast elongates and develops into a multi-branched reticulum (Figures 4, 5D-F). This elongate, branched form persists through successive rounds of nuclear division (Figure $7 A$ ) and well into late stage schizonts where organelle segregation has commenced (Figures 4B-C). In GFP expressing live cells the next observed stage is of multiple, squat rod-shaped apicoplasts in mature schizonts (Figures 5G and 7F). This implies that the multiple division of the apicoplast is either simultaneous
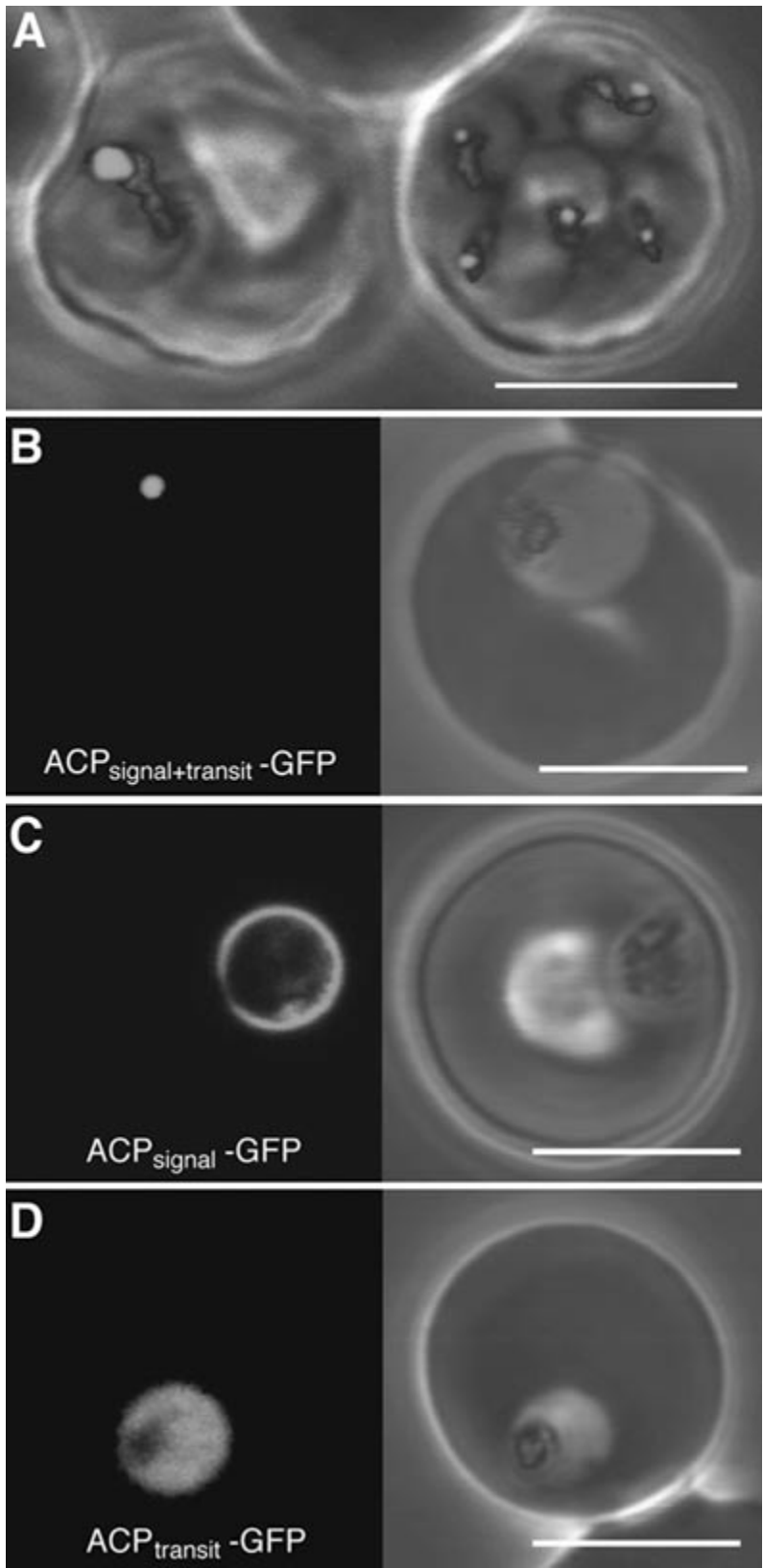

Figure 6. (A) Live intra-erythrocytic Plasmodium falciparum parasites expressing the apicoplast-targeted GFP fusion protein ACP $_{\text {presequence }}$ GFP and co-stained for mitochondria (red) [right-hand erythrocyte contains multiple (5) infections]. (B) Parasite expressing ACP presequence-GFP (presequence containing the signal peptide plus the transit peptide) with GFP accumulating in the apicoplast. (C) Parasite expressing ACP signal- $^{-}$ GFP with GFP accumulating in the parasitophorous vacuole (some GFP re-enters the parasites into the food vacuole). (D). Parasite expressing

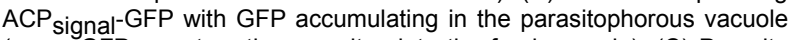
(some GFP re-enters the parasites into the food vacuole). (C) Parasite expressing $\mathrm{ACP}_{\text {transit- }} \mathrm{GFP}$ with GFP accumulating in the cytosol. Scale $\mathrm{bar}=5 \mu \mathrm{m}$.

or occurs as an extremely short chain of events. Upon schizont rupture each merozoite inherits only one apicoplast, and there is no left over organelle with the remaining cell debris (Figure $5 \mathrm{H}$ ).

This intriguing morphology and timing of apicoplast division has likely co-evolved with the unusual pattern of 


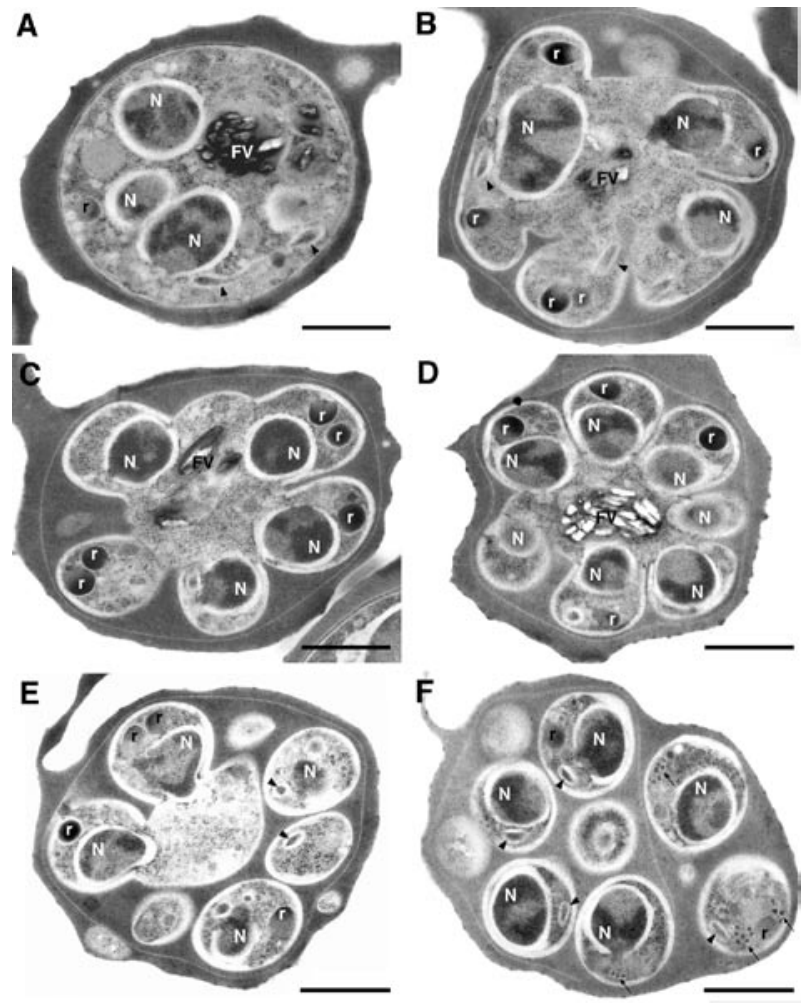

Figure 7. Ultrastructure of intra-erythrocytic Plasmodium falciparum during schizogony. Cryopreserved cells represent pre-segregation stage with multiple nuclei $(A)$, stages during organelle segregation into new apical cups and cytokinesis $(B-E)$, and mature schizonts consisting of separate daughter cells escaping from the parasitophorous vacuole (F). Whilst thin sections cannot provide full detail of apicoplast morphology in these stages, occasional profiles reveal the elongate nature of the apicoplast (A). Arrowhead, apicoplast; N, nucleus; r, rhoptry; FV, food vacuole; arrows, micronemes. Scale bars $=1 \mu \mathrm{m}$.

cell division (schizogony) seen in Plasmodium spp. and many other apicomplexans. The process of schizogony is unusual in that multiple nuclei are produced prior to organelle segregation or cytokinesis (see Figure 7). In $P$. falciparum the number of daughter cells (merozoites) produced by schizonts is variable, ranging anywhere from 8 to 24 (Kudo, 1971). This number must be tied to the final number of nuclei produced. DNA replication and nuclear division in $P$. falciparum is an apparently disordered affair where synchrony of mitosis is quickly lost after the first couple of mitotic events (Read et al., 1993). This more flexible regime is probably the key to the variability in daughter cell number, and may allow schizogony to be better tuned to cell resources and fitness. A disorderly conclusion to nuclear replication (Read et al., 1993) (rather than a co-ordinated final round of mitosis (Bannister et al., 2000)) determines the final number of nuclei, which may be an odd number. For the apicoplast to segregate such that each daughter cell receives one apicoplast, apicoplast division needs to receive some cue as to the number of nuclei and divide accordingly. Delaying apicoplast division until the completion of nuclear division may thus be necessary.

How then does the apicoplast know how many nuclei have been produced? This is most likely through a close association with the centrosomes. Electron microscopist have noted in coccidia that the apicoplast is often seen associated with centrosomes (Vivier and Desportes, 1990; Speer and Dubey, 1999), and a recent elegant study in Toxoplasma gondii (Striepen et al., 2000) confirmed this association by immuno-fluorescence throughout the cell cycle. Moreover, dividing apicoplasts are seen to be drawn apart by centrosomes at each end, with an apicoplast DNA nucleoid just beneath the limiting membranes at these points of centrosome association (Striepen et al., 2000). The apicoplast is then apparently cleaved in two with the development of the pellicle of the daughter cells (Striepen et al., 2000). This model presents an attractive explanation for the complex branched apicoplasts seen in P. falciparum schizonts. An association with centrosomes replicating during nuclear replication would draw the apicoplast into an elaborate conformation as nucleus number increases. By analogy, in T. gondii if apicoplast division is blocked by prolonged microtubule inhibition with dinitroaniline herbicides, apicoplasts with several centrosomes develop and these apicoplasts are elongate and multiply branched (Striepen et al., 2000). In Plasmodium, delaying apicoplast division until the final stages of segregation while maintaining this centrosome association would be necessary to ensure that each nucleus, and hence each daughter cell, receives an equal apicoplast inheritance (including copies of the apicoplast genome). The close association of the mitochondrion with the apicoplast may be a mechanism to ensure that this organelle is appropriately partitioned also. We await confirmation of a link between Plasmodium apicoplasts and centrosomes to further substantiate this model.

\section{Division Molecules}

It is a nice testimony to the prokaryotic nature of plastids that many have retained the molecular apparatus for organelle division that bacteria use for cell division. In bacteria the tubulin homologue FtsZ forms a division ring at the center of the cell coordinated by the a family of Min proteins. In most plant and algal groups surveyed gene homologues for FtsZ and some Min proteins have been found, and these have been shown to be linked to plastid division (Gilson and Beech, 2001; Osteryoung, 2001). Interestingly, FtsZs have been implicated in mitochondrial division also, although many eukaryotes (including animals, fungi and plants) have apparently evolved alternate division mechanisms independent of FtsZ (Osteryoung, 2001). The heterokont algae, which are likely relatives of apicomplexa (see previous section), have been shown to use FtsZ molecules in the division of both their plastids and mitochondria (Beech et al., 2000; Gilson and Beech, 2001). It therefore seemed probable that FtsZs would be found in apicomplexa. To date, however, no FtsZs have been found despite extensive searching of the Plasmodium falciparum genome and PCR screening of Toxoplasma gondii (Striepen et al., 2000). Though such molecules may be discovered, it is possible that apicomplexa have found alternate division strategies. These may involve dynamin-like proteins as have apparently been adopted by yeast for mitochondrion division. Matsuzki et al., (2001) report conspicuous darkly 
staining patches and even rings at the constriction between dividing apicoplasts in T. gondii that might be evidence of some form of division apparatus. Streipen and colleagues (Striepen et al., 2000), on the other hand, have been unable to observe any compelling division structures, and suggest that apicoplast division may be achieved by a slicing force generated by the mitotic spindle pulling the apicoplast against the extending daughter cell pellicle. Presently, this is a topic with more questions than answers.

\section{Protein Targeting to Apicoplasts}

While no plastid is known to have completely lost its prokaryote-type genome, all plastids have undergone extensive transfer of genes to the host cell nucleus (Martin and Herrmann, 1998). This gene transfer has left these organelles heavily dependent upon proteins targeted to the organelle from the host cytosol. In cells with primary plastids (see earlier section) a system of plastid protein import has evolved where a peptide extension, referred to as the transit peptide, occurs at the N-terminus of the protein to be targeted. This transit peptide interacts specifically with the plastid membrane lipids and protein complexes Toc and Tic (Translocon at the outer/inner envelope membrane of chloroplasts) which facilitate protein import into the plastid (Figure 1A) (Bruce, 2001; Jarvis and Soll, 2001). This system is analogous to protein import into mitochondria, and plant cells must discriminate between proteins destined for mitochondria and those destined for plastids. Cells that have acquired a secondary plastid (see earlier section) most likely inherited this Toc/Tic system for protein targeting to plastids. However, upon gene transfer to the new host cell nucleus, cytosolically translated plastid proteins are faced with additional membranes that must be passed on route to the plastid (Figure 1B). In all secondary plastids studied to date, an additional targeting motif has been appended to the transit peptide in response to the extra obstacles of these multi-membrane bound plastids (van Dooren et al., 2001). This motif is a short hydrophobic peptide that apparently acts as a signal peptide for entry into the endomembrane system. This appears to be a logical solution given that the plastid now resides within a derived food vacuole, which is part of the host's endomembrane system (Figure 1B).

Apicoplasts are secondary plastids and are therefore faced with the same extra membrane obstacles for protein import as their algal counter-parts. When the first nucleusencoded genes whose protein products target to the apicoplast were described, from Plasmodium falciparum and Toxoplasma gondii, it was abundantly clear that apicoplasts employ a similar targeting mechanism as algae with secondary plastids. From these genes the predicted proteins (fatty acid biosynthetic proteins ACP, $\mathrm{FabH}$ and $\mathrm{FabZ}$, and ribosomal proteins S9 and L28) all had a substantial N-terminal presequence that by bioinformatic analysis consisted of two parts (Waller et al., 1998). The most $\mathrm{N}$-terminal portions were identified as classic von Heijne-type signal peptides, and these were followed by domains similar to plant-type transit peptides. $P$. falciparum and $T$. gondii are unique amongst secondary plastid containing organisms in that they are amenable to genetic manipulation and this has allowed in apicomplexa a thorough exploration of protein trafficking to secondary plastids.

Targeting Presequences Comprise a Signal Peptide and Transit Peptide

Using GFP as a reporter molecule several studies have demonstrated that the $\mathrm{N}$-terminal bipartite presequences, of apicoplast-targeted proteins, are necessary and sufficient for apicoplast import in Plasmodium falciparum (Figures 3, 4, 5, 6A-B) (Waller et al., 2000) and Toxoplasma gondii (Waller et al., 1998; Yung and Lang-Unnasch, 1999; DeRocher et al., 2000; Jelenska et al., 2001; Yung et al., 2001). It has also been shown that $P$. falciparum presequences successfully targets GFP to T. gondii apicoplasts (Jomaa et al., 1999) and vice versa (Waller et al., 2000). This exchangeability of targeting presequences demonstrates the high level of conservation of trafficking route to apicoplasts between disparate apicomplexa.

The bipartite nature of the presequences has also been examined by deleting either the signal peptide domain or transit peptide domain. If the transit peptide domain of ACP (acyl carrier protein) is removed, leaving only the signal peptide domain, GFP is secreted outside of the cell into the parasitophorous vacuolar space for both Plasmodium falciparum (Figure 6B) (Waller et al., 2000) and Toxoplasma gondii (Roos et al., 1999). This result is also obtained with the S9 presequence (DeRocher et al., 2000; Yung et al., 2001). This validates the bioinformatic identification of a signal peptide in the bipartite presequences, and indicates that the first trafficking step of proteins destined for the apicoplast is entry into the endomembrane system. Moreover, it suggests that once within the endomembrane system, the transit peptide domain is required to sort the protein to the apicoplast. In the absence of this sorting signal GFP follows a default route of secretion out of the cell. If the ACP signal peptide is removed from the GFP construct, leaving only the transit peptide domain, GFP accumulates in the cytosol (Figure 6D) (Roos et al., 1999; Waller et al., 2000). This suggests that the apicoplast sorting machinery that recognizes the transit peptide is within the endomembrane system and cannot facilitate apicoplast sorting from the cytosol.

Protein targeting to apicoplasts is therefore at least a two step process, with co-translational import into the endomembrane system the first step, and subsequent sorting to the apicoplast the second step. A signal peptide followed by a transit peptide is sufficient for these two trafficking events. These bipartite presequences apparently lack any further cryptic sorting signals as is demonstrated by some elegant domain swapping in Toxoplasma gondii. Either the signal peptide was replaced with one from a secreted protein (P30, T. gondii), or the transit peptide replaced with a plant transit peptide (FtsZ, Arabidopsis thaliana) without effect upon apicoplast targeting (Roos et al., 1999). Furthermore, DeRocher et al. (2000) show that the T. gondii S9 transit peptide is recognized by, and facilitates, protein import into isolated pea chloroplasts. It is curious, though not surprising, that in T. gondii the S9 transit peptide (in the 
absence of the signal peptide) can facilitate protein import into the parasite's mitochondrion (DeRocher et al., 2000; Yung et al., 2001). Dual targeting of proteins to plant chloroplasts and mitochondria is seen for a number of proteins (Peeters and Small, 2001) and this result only further emphasizes the relatively generic nature of the apicoplast transit peptide.

\section{Apicoplast Transit Peptides}

While signal peptides are relatively simple, and their mode of action extensively studied from a variety of systems, plastid-targeting transit peptides remain enigmatic (see Bruce, 2001 for review). They vary greatly in size, have no primary sequence conservation, and when analyzed in aqueous conditions apparently lack any stable secondary structure (this may change upon interaction with plastid membrane lipids, see below). Their main defining features are considered to be an enrichment in hydroxylated residues (particularly serine and threonine) and a net positive charge. These criteria have held up quite well across algal and plant transit peptides studied to date (Cline and Henry, 1996; Liaud et al., 1997; Sulli et al., 1999; Deane et al., 2000). How then, do apicomplexan transit peptides compare?

The transit peptides of Plasmodium falciparum and Toxoplasma gondii both show a net positive charge though this bias is predominantly at the $\mathrm{N}$-terminal region of the transit peptide (Waller et al., 1998). Longer transit peptides may become more neutral downstream of this region. A net positive charge in the first 17 residues is such a consistent feature of $P$. falciparum transit peptides that it has been adopted as a useful defining character for predictive software for $P$. falciparum transit peptides (discussed below). An enrichment for serine and threonine residues is also observed in $T$. gondii transit peptides, but this is not the case for $P$. falciparum (Waller et al., 1998; Zuegge et al., 2001). In fact, despite the apparent importance of these residues in plant transit peptides, the mutational removal of all remaining serine and threonines from the transit peptide of $\mathrm{FabH}$ apparently had no effect upon apicoplast targeting (Waller et al., 2000). P. falciparum does, on the other hand, show a strong preference for lysine and asparagine residues in its transit peptides (Waller et al., 1998; Zuegge et al., 2001). While the significance of this is unclear, it may be a consequence of the $P$. falciparum AT bias ( $82 \%$ ) given that both residues can be encoded without a $\mathrm{C}$ or $\mathrm{G}$. The lysines also lend much of the positive charge to the transit peptide. Given that $P$. falciparum transit peptides have been demonstrated to work in $T$. gondii and vice versa (Jomaa et al., 1999; Waller et al., 2000), it seems more likely that the differences between them reflect genome pressures rather that modified trafficking mechanisms.

Transit peptide length has also been studied by a number of groups. From a set of 35 putative Plasmodium falciparum apicoplast-targeted proteins, Zuegge et al., (2001) record a median length of 78 residues, with approximately 20 and 580 the extremities of this range. In Toxoplasma gondii two groups have performed serial deletion experiments with transit peptides and show that there is apparently enormous redundancy in some of these longer transit peptides (DeRocher et al., 2000;
Yung et al., 2001). From the approximately 150 residue presequence of ribosomal protein $\mathrm{S} 9$, all but 55 could be deleted from the $\mathrm{C}$-terminal end without loss of apicoplast targeting. Upon the deletion of a further six residues, transit peptide function was lost and the reporter protein was secreted from the cell (Yung et al., 2001). Whilst this suggested that one or several of these six residues is essential for function, a further construct that lacked only these six out of the 150 residue presequence trafficked normally to the apicoplast (Yung et al., 2001). Therefore, perhaps a minimal length is more important than specific residues. Similar redundancy of transit peptide length has also been shown for T. gondii ACP (Roos et al., 1999).

If we return our attention to plants it is worth noting that several transit peptide features are emerging that may offer insights into general transit peptide function (for review see Bruce, 2001). Four distinct plant transit peptides features are; (1) phosphorylation and dephosphorylation of specific motifs in transit peptides prior to import (this may explain in part the need for hydroxylated residues that can be phosphorylated) (Waegemann and Soll, 1996; Jarvis and Soll, 2001), (2) the presence of Hsp70 recognition domains that mediate binding of these and other cytosolic proteins on route to the chloroplasts (Ivey et al., 2000), (3) specific interactions of transit peptides with chloroplast-specific membrane lipids, and (4) one or more transit peptide domains forming $\alpha$-helical structures upon contact with the chloroplast membrane lipids. It has recently been noted that Plasmodium transit peptides also typically contain predicted Hsp70 binding domains, and that transit peptide function is sensitive to alterations at these sites (Foth et al., 2003). It remains to be tested whether any more of these features play a part in apicoplast transit peptide function.

\section{Tocs and Tics - What Recognizes the Transit Peptide?} The presence of transit peptides in the bipartite leaders of apicoplast-targeted proteins strongly implies that the mechanism of protein import into apicoplasts, at least for the second stage of transport across the inner membranes, has been retained from the primary plastid-containing progenitor. This means that the protein import complexes Toc and Tic are likely to occur still in apicoplasts. Indeed this appears to be the case. ClpC, also known as Hsp93, is a stromal chaperone of plastids that forms part of the Tic complex (Jackson-Constan et al., 2001). The gene for ClpC is encoded on the apicoplast of Plasmodium falciparum and Toxoplasma gondii (Wilson et al., 1996b; Köhler et al., 1997, http://www.sas.upenn.edu/ jkissing/ toxomap.html). Furthermore, a P. falciparum homologue of Tic22 has been found and it has a bipartite leader that targets GFP to the apicoplast suggesting it is a component of apicoplasts (C. J. Tonkin and G. I. McFadden unpublished). A putative homologue of the Toc complex, Toc34, has also been identified from P. falciparum (C. J. Tonkin and G. I. McFadden unpublished). Further homologues will most likely also present themselves from the $P$. falciparum genome data. Additionally, we are now at the stage where "pull down" experiments of these entire complexes can be considered for a more powerful analysis of these protein import machines. 
Bipartite Presequences are Sequentially Removed During Protein Targeting

During protein trafficking signal peptides and transit peptides are both removed after proteins reach their destination. Western blot analyses of both Plasmodium falciparum and Toxoplasma gondii confirm that their bipartite leaders are removed and that this removal occurs sequentially. The signal peptide is presumed to be removed during co-translational import into the endoplasmic reticulum (ER). Consistent with this, full length proteins that include the signal peptide are not detected by Western blot analysis (Waller et al., 1998; 2000). However, protein bands that correspond in size to the mature protein plus the transit peptide are seen in Western blots (Waller et al., 1998; 2000; Vollmer et al., 2001; Yung et al., 2001). These species are thought to represent either proteins that haven't reached their final destination in the apicoplast lumen, or those that await final processing therein. Microscopy studies (either by fluorescence or electron microscopy) do not detect protein trafficking intermediates in the ER or other parts of the cells (Waller et al., 1998; 2000), suggesting that the later explanation is the correct one, although some protein may still be on route through the apicoplast membranes. The smallest apicoplast protein bands detected by Western analysis are the fully processed forms that lack the entire bipartite presequence, and these are typically the predominant bands (Van Dooren et al., 2002).

In plants, the removal of the transit peptide from chloroplast-targeted proteins is achieved by the Stromal Processing Peptidase (SPP) once the proteins arrives in the chloroplast (Richter and Lamppa, 1999). A nucleusencoded homologue of plant SPP has recently been identified from Plasmodium falciparum. The $P$. falciparum SPP homologue bears a bipartite presequence for apicoplast-targeting suggesting it is apicoplast located (van Dooren et al., 2002). This presents a very likely candidate for the role of transit peptide processing in the apicoplast. It is of note that for all apicoplasttargeted proteins studied to date (both for $P$. falciparum and Toxoplasma gondii), substantial amounts of the unprocessed form, with transit peptide still attached, are observed on Western blots (Waller et al., 1998; 2000; He et al., 2001; Vollmer et al., 2001; Yung et al., 2001). This suggests that processing is either delayed or relatively inefficient in apicoplasts in comparison to plant and algal plastids where only the mature, processed proteins are generally detectable. To characterize further the kinetics of protein targeting to apicoplasts and processing in $P$. falciparum, van Dooren et al., (2002) performed ${ }^{35}$ S-Met/ Cys pulse-chase labeling and immuno-precipitation of an apicoplast-targeted ACP-GFP fusion protein. In these experiments the larger band is the first to appear followed by the smaller band, consistent with this representing transit peptide processing. Within 45 minutes of label addition (the shortest period that gave sufficient labeling to observe), some processed form of this targeted protein had already appeared, and it took up to four hours for all labeled protein to be processed. Hence, it takes less than 45 minutes for at least some newly synthesized protein to reach the apicoplast and be processed. DeRocher et al. (2001) have examined the kinetics of apicoplast targeting in Toxoplasma gondii by a novel method. These authors fused the presequence of ribosomal protein S9 to a conditional aggregation domain (CAD) motif (DeRocher et al., 2001). In the absence of a small molecule (AP21998), this fusion protein self associated in the ER of $T$. gondii parasites, presumably shortly after protein synthesis. In this form it was unable to traffic to the apicoplast. Upon the addition of AP21998 the fusion protein can dissociate, and fusion protein reached the apicoplast within 2.5 to 5 minutes. This indicates remarkably fast trafficking in these parasites, and implies that unprocessed stocks of protein seen in Western analyses reveals slow processing.

Purification of two Plasmodium falciparum proteins targeted to the apicoplast has enabled $\mathrm{N}$-terminal protein sequencing of the processed forms of these proteins. Hence for Fabl (Jomaa et al., 1999) and ACP (van Dooren et al., 2002) the cleavage site, most likely recognized by SPP, is known. For plants and algae, cleavage consensus motifs have been characterized that are useful for further predictions of transit peptide boundaries (Emanuelsson et al., 1999). However, the P. falciparum cleavage sites so far conform to none of these "rules" (van Dooren et al., 2002) and offer no clear features that might be useful for further predictions. More data is clearly required to understand better this cleavage event.

From the ER to the Apicoplast - The Events in Between Our current model for protein targeting to the apicoplast can account for protein entry into the ER (via the signal peptide) and the subsequent passage into the apicoplast across the inner membranes most likely spanned by Toc and Tic import complexes (via the transit peptide). Yet there remain unresolved questions about the transport events in between. (1) How do proteins get from the ER to the apicoplast for Toc/Tic mediated final transport? (2) If the inner two membranes of apicoplasts are derived from the primary plastid and retain their Toc and Tic complexes, how is the third membrane (counting from the inside) of four membrane-bound apicoplasts crossed by proteins?

From the ER to the Apicoplast

To address the first question there are several possibilities that we can consider. The first and simplest has a precedent in several algal groups. This is that proteins are co-translationally inserted directly into the outer membrane of the apicoplast. Secondary plastids in many algal groups have ribosomes on the outermost membrane, which is contiguous with the rough ER, and co-translational insertion into the endomembrane lumen containing the plastid is thought to occur (van Dooren et al., 2001). No such ribosomes are observed on the apicoplast limiting membrane so an alternative delivery mechanism must occur. Furthermore, DeRocher's CAD fusion protein accumulated in the ER, not in an outer shell of the apicoplast (see above) (DeRocher et al., 2001). Another possibility is that the apicoplast outer membrane is continuous with the ER, and therefore ER proteins have direct access to the apicoplast. Such connections have not been observed by microscopy, although transient tubular connections such as occur between plastids in plants (Kohler et al., 1997) may be labile and difficult to observe. 
If no continuity occurs between the ER and the apicoplast then vesicular traffic must be considered and recent data suggests that NSF (N-ethylmaleimidesensitive factor)-mediated vesicle docking does occur at the outer apicoplast membrane (Hayashi et al., 2001). What then directs vesicles to the apicoplast? The simplest solution is nothing, simply that the apicoplast sits in the default secretory pathway. This implies that in the absence of any further signal, all proteins from the ER will wash past the apicoplast, allowing for proteins baring transit peptides to be selected from this mix. In this scenario the apicoplast could be positioned anywhere post ER, including before or after (or theoretically even within) the Golgi apparatus. The alternative possibility is that directed vesicle traffic to the apicoplast does occur following a sorting event of apicoplast proteins from other proteins in the endomembrane system. Given that a plant transit peptide can mediate apicoplast transport from the ER (Roos et al., 1999) we know that no novel signals have been added to apicomplexan transit peptides. Could then protein sorting utilize the transit peptide itself? In plants, a class of cytosolic, targeting factors (including Hsp70s and 14-3-3 proteins) have recently been shown to bind the transit peptides of chloroplast-targeted proteins, prior to their arrival at the chloroplast membrane, and deliver them to chloroplasts in a heightened import-competent state (Bruce, 2001; Jackson-Constan et al., 2001; Jarvis and Soll, 2001). This shows that recognition of transit peptides can occur remote from plastids. It is therefore possible that a receptor-mediated transport system in apicomplexa could have evolved from such a plant system, although the system would need to located within the lumen of the endomembrane system for apicomplexa.

Until recently there has been little data to support any of the above scenarios, but attention is now being drawn towards these outstanding questions. Parasite ER retention signals (HDEL) have been appended to apicoplast targeted fusions in Toxoplasma gondii and show no effect on apicoplast targeting (D. S. Roos, pers. comm.; DeRocher et al., 2001). This suggest that apicoplast-sorting may occur before the cis Golgi where HDEL resorting to the ER occurs (Van Wye et al., 1996). Conversely, apicoplast targeting has recently been shown to be sensitive to brefeldin A in Plasmodium falciparum (Cheresh et al., 2002). Brefeldin A blocks protein movement beyond the Golgi in $P$. falciparum (Crary and Haldar, 1992), therefore this data argues that protein targeting to the apicoplast occurs via the Golgi. Cheresh et al. (2002) also provide data for a rather surprising hypothesis. Using stage-regulated expression of a transgene during young ring stage $P$. falciparum parasites these authors report protein accumulation in the parasitophorous vacuole prior to protein sorting to the apicoplast. This routing was not evident by our previous studies of the same fusion protein under direction of a different promoter (Waller et al., 2000). However, the use of a differently timed promoter system may account for these differences. No evidence of such a routing has been reported for $T$. gondii. Cheresh et al.'s hypothesis presents a somewhat unanticipated route for apicoplast targeting. Nevertheless, it needs to be remembered that $P$. falciparum possesses a highly developed secretory system that traffics proteins specifically to several destinations beyond the parasite in the erythrocyte cytosol and plasma membrane (Foley and Tilley, 1998). Recent studies suggest that proteins destined for these sites also travel via the parasitophorous vacuole (Wickham et al., 2001). Could it be that Plasmodium has redefined this "external" compartment as a sorting station for secretory proteins? If so, we may find that other internal organelles, such as micronemes and rhoptries, also use this pathway for protein trafficking via the parasitophorous vacuole.

\section{One Membrane To Go!}

The second unresolved question concerns how the third apicoplast membrane is crossed by apicoplasttargeted proteins. This is a question that has vexed all who have considered protein trafficking to four membrane-bound plastids (van Dooren et al., 2001). A simple solution is presented where pores or non specific protein transporters allow proteins to simply diffuse across the third membrane, as if it wasn't there (Kroth and Strotmann, 1999). The origin of such pores is unstated. Perhaps a more attractive option, though equally untested, is that the Toc/Tic machinery has come to span all three inner membranes. This might occur by simply having Toc complexes in both the second and third membranes. Proteins would then pass through two Toc complexes before being passed through a Tic complex. Both of these models suggest that the third membrane is redundant, and cannot explain why it has not been lost, as is the case in some algal groups. It is possible that the third membrane retains some useful role in apicoplast trafficking, but at present, such a role eludes us.

\section{Genome Screening for Apicoplast-Targeted Sequences} Except for a select band of secondary-plastid-proteintargeting aficionados, the greatest interest in protein trafficking routes to the apicoplast is due to their ability to tell us more about the protein content of apicoplasts. In Arabidopsis thaliana 3574 proteins are thought to be targeted to chloroplasts (The Arabidopsis Genome Initiative, 2000). Even though the apicoplast lacks proteins associated with photosynthesis and, in the case of Plasmodium falciparum at least, the shikimate pathway for aromatic amino acid synthesis (Keeling et al., 1998), its protein count could exceed one thousand. When one considers that the apicoplast genome encodes a mere 64 genes, and many of these are rRNAs and tRNAs, it is obvious that the major portion of the apicoplast proteome is coded for in the nucleus. The distinctive bipartite presequences necessary for apicoplast targeting thus offer a useful handle for identifying putative apicoplast proteins from genomics data.

In response to the tide of Plasmodium falciparum genome data, efforts have been made to develop predictive software for screening the genome data. Signal peptide predictors such as neural network-based SignalP, and "knowledge-based" PSORT have proved generally reliable for identifying the signal peptides on the bipartite presequences (Waller et al., 1998; Zuegge et al., 2001). However, the neural network-based transit peptides predictor ChloroP is generally not very reliable for nonplant transit peptides (Bruce, 2001). Indeed, ChoroP 
performs poorly in predicting Plasmodium falciparum transit peptides, probably because it was trained with plant data sets (Zuegge et al., 2001). Therefore, Zuegge et al. (2001) set about training a neural network specifically for $P$. falciparum targeting presequences. Using a training set of 84 sequences most probably targeted to the apicoplast, and a negative set of 102 non-apicoplast proteins, Zuegge et al. developed a predictive system called PATS (predict apicoplast-targeted sequences) that upon reclassification of the training data was $97 \%$ accurate. When used in conjunction with SignalP for signal peptide assignments this power was increased. When PATS was applied to the $P$. falciparum chromosome 2 and 3 data it predicted that 69 genes (15\% of total genes on these chromosomes) encoded apicoplast-targeted proteins (Zuegge et al., 2001). Previously only a few of the genes had been annotated as encoding apicoplast targeted proteins (Gardner et al., 1998).

An alternate "knowledge-based" strategy has also been developed where observed features of Plasmodium falciparum presequences have been used to model a set of criteria for discriminating apicoplast-targeting presequences (Foth et al., 2003). Foth et al. have defined four key criteria in their predictor (called PlasmoAP and accessible online at http://www.PlasmoDB.org). These criteria are as follows. (1) SignalP identifies a likely signal peptide (which is removed at the predicted cleavage site for the rest of the analysis which focuses on the transit peptide component). (2) Within the first 22 residues of the transit peptide the ratio of acid to basic residue must not exceed 0.7. (3) Within the first 80 amino acids a stretch of 40 residues with a total of at least 9 asparagines and lor lysines occurs. (4) The above 40 residue window must have a ratio of acid to basic residues of no greater than 0.9. Using these criteria, this predictor enabled good recovery of the training set used by Zuegge et al. (2001) and when applied to chromosome 2 and 3 data recovered a very similar set of genes to PATS (Foth et al., 2003). Moreover, Foth et al. (2003) have set about testing the parameters of their predictor in vivo through transit peptide mutagenesis experiments. These experiments validate the importance of positively charged residues at the N-terminal extremity of the transit peptide, but also point to possible refinements of the criteria to enhance the power of this predictor.

These custom made predictors of Plasmodium falciparum apicoplast-targeting bipartite presequences have provided a valuable primary screen of the $P$. falciparum genome. Together they identify over 500 genes that likely encode plastid-targeted proteins (Gardner et al., 2002; Foth et al., 2003). This represents approximately $10 \%$ of the gene content of the $P$. falciparum genome. However, this likely represents a minimal figure given that genes with introns that interrupt the presequence area (of which there are many already known) will be overlooked by these methods. Some genes can even share a single bipartite presequence coding region that is alternatively spliced onto one of two unrelated gene mRNAs. van Dooren et al. (2002) have recently identified such a case with $P$. falciparum SPP and ALAD (delta-aminolevulinic acid dehydratase). Such problems, however, are common to the annotation of any eukaryotic genomic sequences and demonstrate that bioinformatics tools represent only the first step in the analysis of genome data. Nevertheless these methods have offered us our first overview of the apicoplast protein content.

\section{Apicoplast Metabolism - A Target for Drugs}

Why apicomplexan parasites should possess a plastid was a confronting question to greet malariologists who first took an interest in this unexpected discovery. What could "plant biology" have to offer such a superb group of intracellular animal parasites? Indeed many questioned the utility of the apicoplast, and considered that it may simply be useless evolutionary baggage. However, it is now clear that the apicoplast is indispensable to parasites. This was first demonstrated in Toxoplasma gondii by selectively blocking apicoplast DNA replication leading to eventual loss of apicoplast DNA and cell death (Fichera and Roos, 1997). Similarly, in Plasmodium falciparum agents that reduce apicoplast transcription kill parasites (McConkey et al., 1997). More recently and elegantly, He et al. (2001) engineered a T. gondii apicoplast segregation mutant that resulted in parasites completely lacking an apicoplast. Interestingly, these parasites were able to invade host cells and divide once or twice, however, growth then stopped and the parasites died. In addition there is a great deal of indirect drug inhibition data that supports apicoplast metabolism being vital to parasites (see Table 1). But why do apicomplexa still require this plastid, despite not using it for photosynthesis? To address this question fully, it is useful to consider the processes of endosymbiotic partnership.

The establishment of an autotrophic endosymbiont offers a radical change of lifestyle for any heterotroph. A cell formerly dependant on prey capture for reduced carbon as an energy source, and potentially numerous other macromolecular building blocks (such as the many "vitamins", certain amino acids and fatty acids, etc), now has the chance to exploit the endosymbiont as a supplier of these items. Indeed, should this cell now become exclusively autotrophic, it will be completely dependant on this "in-house" production, just as the autotrophic endosymbiont would have been before. This partnership, however, also initially creates many duplications of equivalent, though sometimes very divergent (due to the prokaryotic nature of plastids), metabolic pathways. In evolution, redundancy is generally countered by streamlining, and it may be either the host or endosymbiont version of a given pathway that is lost. Cases of the endosymbiont pathway being selected over that of the host include the chloroplast pathways for fatty acid and heme synthesis in most plants (Brown et al., 1990; Harwood, 1996). "Mix and match" combinations of both host and endosymbiont components of a single pathway can also occur, such as fatty acid synthesis in grasses (the first enzyme, ACC, is host-derived, the subsequent ones, FAS, are plastid-derived) (Harwood, 1996). Thus, the endosymbiont may come to fulfill further roles beyond those that drove the initial symbiosis. Should this cell revert to a heterotrophic lifestyle, all or part of the initial utility of the endosymbiont may be lost. However, endosymbiont functions that have displaced host ones (and are not satisfied by heterotrophy) will remain 
necessary. If these functions have not, or cannot, be relocated from the endosymbiont, then the endosymbiont must be retained. In other words, the endosymbiont may have integrated beyond the point of no return.

Apicomplexans have apparently followed the course of this scenario. An ancestral heterotrophic cell acquired the apicoplast progenitor which was most probably photosynthetic (see first section). Perhaps after a long period of autotrophy, apicomplexans diverged from their algal sisters with a high degree of specialization as parasites. Clearly photosynthesis became redundant and was lost, but the apicoplast has persisted. Given that the apicoplast is indispensable, either some unique metabolism(s) acquired with the endosymbiont continues to drive its utility in the cell, or else it has come to fulfill one or more previous functions of the hosts and therefore cannot be lost. Of course it might be that both of these are true. Whatever the case, all of the additional machinery for apicoplast maintenance is also indispensable.

A thorough survey of apicoplast metabolism is therefore required in order to address the question of its significance in parasites. Separating those functions that directly benefit the host cell, from those that are simply necessary for apicoplast maintenance is a greater challenge. Nevertheless, the parasite's dependence on this organelle, and its plastid-type prokaryotic nature, make it an excellent target for drugs. Presently the majority of our knowledge of apicoplast metabolism has been gleaned from genomic date. This includes genes from the apicoplast genome, but more significantly genes from the nuclear genome through the identification of apicoplast-targeting presequences. The completion of the Plasmodium falciparum genome and automated screening for apicoplast genes (see last section) has provided us with an excellent starting point for examining apicoplast metabolism. The following provides a summary of our current understanding of this metabolism and, where known, drugs that interrupt these pathways in parasites.

\section{DNA Replication}

A circular genome has served as the apicoplasts defining feature and its replication can be considered the first metabolic process of the apicoplast. Interestingly, Williamson et al. (2001) have recently reported that half of the copies of the Toxoplasma gondii apicoplast genome actually occur as precise tandem linear arrays. From this they invoke a rolling circle hypothesis for DNA replication in this parasite with the origin of replication at the centre of the inverted repeat of rRNA genes. It is noted that other apicomplexa also display an element of linearity with their apicoplast genomes (Eimeria tenella (Dunn et al., 1998) and Neospora caninum (Gleeson, 2000)) although in Plasmodium falciparum at least $90 \%$ of its apicoplast DNA is said to be in the circular conformation (Williamson et al., 2001). It remains to be seen what mode of DNA replication occurs in these.

\section{Drugs That Target DNA Replication}

The fluoroquinolone ciprofloxacin is a selective-inhibitor of prokaryote-type DNA gyrases (type II topoisomerases in the eukaryotic nomenclature) that results in stabilized nicked DNA complexes. Coding sequences for two putative apicoplast-targeted proteins (GyrA and GyrB) have been identified from Plasmodium falciparum genome data (Ralph et al., 2001) and suggest that the apicoplast utilizes these molecules for its DNA replication. Ciprofloxacin has been shown to inhibit apicoplast DNA replication in $P$. falciparum and Toxoplasma gondii without affecting parasite nuclear DNA replication (Divo et al., 1988; Fichera and Roos, 1997; Weissig et al., 1997). Parasite death results from this drug treatment. Several derivatives of quinalones and fluoroquinolones have also been shown to have parasiticidal activity against Toxoplasma gondii, further supporting apicoplast DNA replication as a selective drug target in apicomplexan parasites (Khan et al., 1996; Gozalbes et al., 2000).

\section{Transcription}

Northern blot analyses of Plasmodium falciparum report transcription of several genes of the apicoplast genome, often as large polycistronic transcripts (Gardner et al., 1991; Feagin and Drew, 1995; Wilson et al., 1996b). Transcript abundances of some genes (ssu and Isu rRNA genes, rpoB and rpoC) have been shown to change throughout the cell cycle and provide evidence of regulated transcription of apicoplast genes (Feagin and Drew, 1995). Plastid transcription utilizes a eubacterial $\left(\alpha_{2} \beta \beta^{\prime}\right)$ system of DNA-dependant RNA polymerases that was inherited with the cyanobacterial endosymbiont (Gray and Lang, 1998). The apicoplast genome encodes part of this system ( $\beta$ subunit by $r p o B$, and $\beta$ ' subunit by rpoC1 and rpoC2) while the remainder ( $\alpha_{2}$ subunit, as well as sigma factor) are apparently encoded in the nucleus and targeted back to the apicoplast. Despite the eubacterial origin of mitochondria, these endosymbiotic organelles have apparently adopted a single protein phage-like RNA polymerase (one unusual protist, Reclinomonas americana, is the only exception to this rule (Gray and Lang, 1998)), and there is evidence for this form of transcription in the P. falciparum mitochondrion ( $\mathrm{Li}$ et al., 2001). Recently, plant chloroplasts have been found also to employ a copy of this phage-like RNA polymerase, which is used in addition to the eubacterial system. It is currently unknown if $P$. falciparum uses both systems for plastid transcription, or only the eubacterial form.

\section{Drugs that Target Transcription}

The eubacterial form of transcription is highly sensitive to the antibiotic rifampicin and this drug has antimalarial activity both in vitro and in vivo (Strath et al., 1993; Pukrittayakamee et al., 1994). Furthermore, rifampicin is shown to selectively diminish transcripts of apicoplast-encoded genes and, hence, the apicoplast is most probably the site of drug action (Wilson et al., 1996b; McConkey et al., 1997). A derivative of rifampicin, rifabutin, also shows activity against Toxoplasma gondii in vitro and in vivo (Araujo et al., 1994; Olliaro et al., 1994).

\section{Protein Translation}

The case for protein translation in the apicoplast is currently built on indirect evidence, yet is nevertheless extremely strong. Most of the apicoplast genome is dedicated to the machinery of translation, including a 
complete set of tRNAs, rRNA genes, numerous ribosomal protein genes, and the translation elongation factor TufA (Wilson et al., 1996b). Although apicoplast-encoded genes alone are insufficient for an entire translational machinery, further components have been shown to be nucleus-encoded (for example ribosomal proteins S9 and L28) and targeted to the apicoplast as proteins (Waller et al., 1998) as is the case for all plastids. Prokaryote $70 \mathrm{~S}$ ribosomal particles are observed in the apicoplasts by electron microscopy suggesting proper ribosomal assembly (McFadden et al., 1996; Hopkins et al., 1999), and polysomes carrying apicoplast-specific mRNAs and rRNAs can be purified from blood-stage parasites supporting their functionality (Roy et al., 1999).

\section{Drugs That Target Protein Translation}

Numerous anti-bacterial agents work by targeting protein synthesis. Even prior to the discovery of the apicoplast several of these were known to be parasiticidal (clindamycin, chloramphenicol, doxycycline and tetracycline) and some are used clinically for the treatment of malaria and toxoplasmosis (including doxycycline, clindamycin and spiramycin). Understanding their modes of action in parasites is vital for their proper application. Lincosamides (clindamycin) and macrolides (azithromycin) inhibit protein synthesis by binding to the peptidyl transferase domain of the prokaryote-type 23S rRNA. Two thiopeptides (thiostrepton and micrococcin) also bind to 23S rRNAs, specifically the GTPase domain where they interact with key nucleotides represented in eubacteria and some plastids. Plasmodium falciparum shares this genotype, which is shown to bind to thiostrepton, and parasites are highly sensitive to thiostrepton (both in vitro and in vivo) and micrococcin (Clough et al., 1997; McConkey et al., 1997; Rogers et al., 1997; Sullivan et al., 2000). Toxoplasma gondii, on the other hand, does not share the complete eubacterial genotype and is insensitive to thiostrepton (Clough et al., 1997; D. S. Roos, pers. comm.). Other inhibitors of prokaryote-type translation are parasiticidal and may inhibit apicoplast translation (Table 1), but their precise mode of action is undefined.

One interesting feature of some of these inhibitors is a "delayed death" phenotype seen in Toxoplasma gondii (see Table 1) (Pfefferkorn and Borotz, 1994; Fichera et al., 1995; Fichera and Roos, 1997). This effect is identical to the growth pattern of apicoplast segregation mutants lacking an apicoplast (He et al., 2001). This suggest that the delayed death relates to apicoplast function (one theory suggests a role in parasitophorous vacuole function) and not simply to drug accessibility to the parasites. In Plasmodium falciparum a case for delayed death is less clear. Chloramphenicol does not have a delayed effect (Budimulja et al., 1997) (compared to $T$. gondii), and while thiostrepton is reported as slow acting, a delay in drug action has not been demonstrated (Sullivan et al., 2000). Inhibitors of fatty acid synthesis (see below) on the other hand do have very rapid inhibitory effects on $P$. falciparum. Differences in apicoplast-drug response kinetics between $P$. falciparum and $T$. gondii may point to some differences in the roles that these apicoplasts fulfill in parasites.

\section{Other Apicoplast-Encoded Genes}

Aside from genes clearly coding for transcription and translation functions on the apicoplast genome, there are 9 remaining open reading frames (ORFs) that could contribute to some further apicoplast metabolism. Within these final ORFs must lie the reason(s) for retaining the apicoplast genome and all of the associated metabolism necessary for its maintenance and expression. Some of these ORFs, however, have been suggested to represent further ribosomal and associated proteins, based on their size and conserved positions, but are too divergent for confident assignment (Blanchard and Hicks, 1999).

$c / p C$, on the other hand, is distinguished by being one apicoplast gene that is clearly not involved in either transcription or translation. ClpC (also known as Hsp93) forms part of the Tic complex for protein import into plastids (Jackson-Constan et al., 2001). ClpC's role, therefore, is to help supplement apicoplast translation, for all apicoplast proteins that are not encoded on the apicoplast genome.

One apicoplast ORF, known as orf470 or ycf24 and more recently re-assigned sufB shares a high level of similarity with a gene encoded in plastids in some algae and as part of an operon conserved in most bacteria (Wilson et al., 1996b; Blanchard and Hicks, 1999; Ellis et al., 2001). Knock-out experiments in the cyanobacterium Synechocystis sp. PCC6803 suggest that this gene is essential and it was tentatively assigned a gene component of an ABC transporter (Law et al., 2000). Ellis et al. (2001) revise this view and now consider this gene a likely member of the suf operon of $E$. coli that is involved in iron homeostasis and [Fe-S] cluster formation. Plastid metalloproteins with [Fe-S] clusters include ferredoxin which is known to target to apicoplasts (see below) (Vollmer et al., 2001). SufB could therefore be essential for post-translational modification of imported protein and provides a rationale for persistence of the apicoplast genome that now awaits further confirmation.

\section{Fatty Acid Biosynthesis}

Fatty acids play a critical role in cells as metabolic precursors for biological membranes and energy stores. Their synthesis occurs as iterative elongations of acyl chains utilizing the 2-carbon donor malonyl-CoA. Fatty acid synthase (FAS) is the principal enzymatic unit of this process and in bacterial systems separate proteins constitute the several enzyme activities of FAS. This system is known as the type II or dissociated pathway and is believed to represent the ancestral state (Smith, 1994). In animals, gene fusion events have resulted in FAS evolving into a single large multi-functional protein (Smith, 1994) and this cytosolic pathway is known as the type I or associated pathway. Plants utilize a plastidbased pathway and this is of the bacterial type II system, which reflects the prokaryotic origin of plastids (Harwood, 1996).

Plasmodium spp. have long been believed unable to make their own fatty acids, depending instead on scavenged fatty acids from the host erythrocytes and serum (Holz, 1977; Vial and Ancelin, 1992; Fish, 1995). This notion is now being revised, with strong evidence for a type II pathway for de novo fatty acid synthesis 


\begin{tabular}{|c|c|c|c|c|c|}
\hline Metabolic Activity & Putative Target & Drug & IC50 ${ }^{\mathrm{a}}$ & Comments & Refs \\
\hline \multirow[t]{2}{*}{ DNA Replication } & \multirow[t]{2}{*}{ Apicoplast DNA gyrase } & Ciprofloxacin & $\begin{array}{l}\text { Pf 8-38uM } \\
T g ~ 30 \mu \mathrm{M}\end{array}$ & $\begin{array}{l}\text { Confirmed to block apicoplast DNA } \\
\text { replication }\end{array}$ & $3^{1,2}$ \\
\hline & & Trovofloxacin & $\operatorname{Tg} 0.77-0.98 \mu \mathrm{g} / \mathrm{ml}$ & Causes delayed death in $T g$ & 4 \\
\hline \multirow[t]{2}{*}{ RNA Transcription } & \multirow[t]{2}{*}{$\begin{array}{l}\text { Apicoplast RNA polymerase } \\
\beta \text {-subunit }\end{array}$} & Rifampicin & $\begin{array}{l}\operatorname{Pf} 3 \mu \mathrm{M} \\
\operatorname{Tg} 3 \mu \mathrm{M}^{\mathrm{b}} \\
\end{array}$ & $\begin{array}{l}\text { Confirmed by Northern analysis } \\
\text { in } P f\end{array}$ & 5,6 \\
\hline & & Rifabutin & $\operatorname{Tg} 26.5 \mu \mathrm{g} / \mathrm{ml}$ & & 7,8 \\
\hline \multirow[t]{9}{*}{ Protein Translation } & \multirow[t]{6}{*}{ Apicoplast 23S rRNA } & Clindamycin & $\begin{array}{l}P f 20 M^{b} \\
T g 10 n M^{b}\end{array}$ & Causes delayed death in $T g$ & $9,10,11,12$ \\
\hline & & Azithromycin & $\begin{array}{l}\text { Pf } 2 \mu \mathrm{M}^{\mathrm{b}} \\
\operatorname{Tg} 2 \mu \mathrm{M}\end{array}$ & Causes delayed death in $T g$ & $9,10,12,13$ \\
\hline & & Spiramycin & $\operatorname{Tg} 40 \mathrm{ng} / \mathrm{ml}$ & Causes delayed death in $T g$ & 9,10 \\
\hline & & Thiostrepton & $\begin{array}{l}\operatorname{Pf} 2 \mu \mathrm{M} \\
\operatorname{Tg} \mathrm{NS}^{\mathrm{b}}\end{array}$ & Drug-target interaction cofirmed & $14,15,16,17$ \\
\hline & & Micrococcin & Pf $35 \mathrm{nM}$ & & 18 \\
\hline & & Chloramphenicol & $\begin{array}{l}\text { Pf } 10 \mu \mathrm{M}^{\mathrm{b}} \\
\operatorname{Tg} 5 \mu \mathrm{M}^{\mathrm{b}}\end{array}$ & Causes delayed death in $T g$ & $\begin{array}{l}19 \\
10,12,13 \\
\end{array}$ \\
\hline & \multirow[t]{2}{*}{ Apicoplast 16S rRNA } & Doxycycline & Pf $11.3 \mu \mathrm{M}$ & May also target mitochondrion & 19,20 \\
\hline & & Tetracycline & $\begin{array}{l}\text { Pf } 10 \mu \mathrm{M} \\
\operatorname{Tg} 20 \mu \mathrm{M}\end{array}$ & $\begin{array}{l}\text { No delayed death in } \mathrm{Tg} \text {, } \\
\text { may also target mitochondrion }\end{array}$ & $\begin{array}{l}13,19 \\
12\end{array}$ \\
\hline & $\begin{array}{l}\text { Apicoplast elongation factor } \\
\text { TufA }\end{array}$ & Amythiamicin & Pf 10nM & $\begin{array}{l}\text { Inferred by polysome distruption } \\
\text { in } P f\end{array}$ & 21 \\
\hline \multirow[t]{10}{*}{ Fatty acid biosynthesis } & \multirow{2}{*}{$\begin{array}{l}\text { Apicoplast-targeted } \\
\beta \text {-ketoacyl-ACP } \\
\text { synthase II and III } \\
\text { (FabF and FabH) }\end{array}$} & Thiolactomycin & $\begin{array}{l}\text { Pf } 50 \mu \mathrm{M} \\
\operatorname{Tg} 100 \mu \mathrm{M}^{\mathrm{b}}\end{array}$ & & 22 \\
\hline & & $\begin{array}{l}\text { Thiolactomycin } \\
\text { analogues }\end{array}$ & $P f \geq 8 \mu \mathrm{M}$ & & 23 \\
\hline & $\begin{array}{l}\text { Apicoplast-targeted enoyl- } \\
\text { ACP reductase (Fabl) }\end{array}$ & Triclosan & $P f 1 \mu \mathrm{M}$ & Fabl inhibition confirmed & 24,25 \\
\hline & $\begin{array}{l}\text { Apicoplast-targeted } \beta \text { - } \\
\text { ketoacyl-ACP synthase II } \\
\text { (FabF) }\end{array}$ & Cerulenin & $11 \mu \mathrm{M}$ & & 23 \\
\hline & \multirow{6}{*}{$\begin{array}{l}\text { Apicoplast-targeted Acetyl- } \\
\text { CoA carboxylase (ACC) }\end{array}$} & Clodinafop & $\operatorname{Tg} 10 \mu \mathrm{M}$ & ACC inhibition confirmed & 26,27 \\
\hline & & Quizlofop & $\operatorname{Tg} 100 \mu \mathrm{M}$ & ACC inhibition confirmed & 26 \\
\hline & & Haloxypop & $\operatorname{Tg} 100 \mu \mathrm{M}$ & ACC inhibition confirmed & 26,27 \\
\hline & & Fenoxaprop & Pf $144 \mu \mathrm{M}$ & & 23 \\
\hline & & Tralkoxydim & Pf $181 \mu \mathrm{M}$ & & 23 \\
\hline & & Diclofop & Pf $210 \mu \mathrm{M}$ & & 23 \\
\hline \multirow[t]{2}{*}{ Isoprenoid biosynthesis } & \multirow[t]{2}{*}{$\begin{array}{l}\text { Apicoplast-targeted DOXP } \\
\text { reductoisiomerase }\end{array}$} & Fosmidomycin & Pf 290-370nM & $\begin{array}{l}\text { DOXP reductoisomerase inhibition } \\
\text { confirmed }\end{array}$ & 28 \\
\hline & & FR-900098 & Pf 90-170nM & $\begin{array}{l}\text { DOXP reductoisomerase inhibition } \\
\text { confirmed }\end{array}$ & 28 \\
\hline \multicolumn{6}{|c|}{$\begin{array}{l}\text { a IC50s are recorded from a diversity of assays (including growth inhibition, death and enzyme assays) and are not directly comparable } \\
\text { b. S. Roos unpublished results } \\
\text { Abbreviations: ACP, acyl carrier protein;NS, not sensitive; }\end{array}$} \\
\hline \multicolumn{6}{|c|}{$\begin{array}{l}\text { References: (1) Divo et al., 1988, (2) Weissig et al., 1997, (3) Fichera and Roos, 1997, (4) Khan et al., 1996, (5) Strath et al., 1993, (6)Pukrittayakamee } \\
\text { et al., 1994, (7) Araujo et al., 1994, (8) Olliaro et al., 1994, (9) Pfefferkorn and Borotz, 1994, 10) Fichera et al., 1995, (11) Fichera and Roos, 1997, (12) } \\
\text { Woods et al., 1996, (13) Beckers et al., 1995, (14) Clough et al., 1997, (15) McConkey et al., 1997, (16) Rogers et al., 1997, (17) Sullivan et al., 2000, } \\
\text { (18) Rogers et al., 1998, (19) Budimulja et al., 1997, (20) Pradines et al., 2000 (21) Clough et al., 1999, (22) Waller et al., 1998, (23) Waller et al., 2003, } \\
\text { (24) Surolia and Surolia, 2001, (25) McLeod et al., 2001, (26) Zuther et al., 1999, (27) Zagnitko et al., 2001, (28) Jomaa et al., 1999. }\end{array}$} \\
\hline
\end{tabular}

occurring in apicoplasts. An indication of fatty acid synthesis in apicoplasts first occurred with the discovery of nucleus-encoded FAS genes whose products are targeted to the apicoplast. These include acyl carrier protein (ACP) and $\beta$-ketoacyl-ACP synthases III (FabH) in Plasmodium falciparum (Waller et al., 2000), and ACP in Toxoplasma gondii (Waller et al., 1998). Since then, genes corresponding to all enzymes of FAS have been identified, except for a thioesterase required for acyl chain termination (McLeod et al., 2001; Surolia and Surolia, 2001; Gardner et al., 2002). Additionally, acetylCoA carboxylase (ACC), which generates the carbon donor malonyl-CoA for FAS, is also represented in $P$. falciparum genome data (Zuther et al., 1999) and shown to be apicoplast-targeted in T. gondii (Jelenska et al., 2001). Biochemical support for fatty acid synthesis in $P$. falciparum has followed with functional characterization of several enzymes of FAS (Surolia and Surolia, 2001; Waters et al., 2002; Prigge et al., 2003). Moreover, ${ }^{14} \mathrm{C}$-labeled precursors (acetate and malonyl-CoA) are shown in $P$. falciparum to incorporate into fatty acids (predominantly $\mathrm{C} 10$ to $\mathrm{C} 14$ ) in both in vivo and in vitro systems (Surolia and Surolia, 2001). This incorporation is sensitive to triclosan, a known inhibitor of type II FAS, that is shown to bind specifically to $P$. falciparum Fabl (Surolia and Surolia, 2001; Perozzo et al., 2002). In concert, these data strongly implicate that apicoplast as the site of this fatty acid biosynthetic activity. 
No evidence of a type I FAS has been found in the Plasmodium falciparum genome data. A type II pathway in the apicoplast is likely therefore to fulfill all of the parasite's need for de novo synthesized fatty acids. In contrast, Cryptosporidium parvum apparently lacks genes for a type II pathway, yet does have a large coding sequence for a type I FAS (note, it remains formally possible that this is a polyketide synthase) (Zhu et al., 2000b). Interestingly, no evidence has yet been found for an apicoplast in C. parvum (Zhu et al., 2000a) which suggests that these parasites have maintained a cytosolic type I system in the absence (most likely following apicoplast loss) of an apicoplast-based type II system.

Drugs that Target Fatty Acid Biosynthesis

The presence of a distinct, prokaryote pathway for the biosynthesis of fatty acids in parasites offers tremendous potential as a focus for parasite-selective drugs (Table 1). Thiolactomycin is one such drug that inhibits type II FAS in plants and bacteria and by enzyme kinetics and crystal structure studies is known to bind specifically to $\beta$-ketoacyl-ACP synthases (most strongly to synthases I and II). Thiolactomycin kills parasites in vitro (Table 1) (Waller et al., 1998) and several analogues show up to five-fold greater efficacy (Waller et al., 2003). Triclosan is another drug selective for the prokaryote pathway that shows even greater efficacy against parasites and is also effective as an anti-malarial in mouse models (McLeod et al., 2001; Surolia and Surolia, 2001; Perozzo et al., 2002).

This drug has a long record of safety for human use (as an anti-microbial in toothpastes and other products) and triclosan analogues are being explored for anti-malarial use (Perozzo et al., 2002). Both thiolactomycin and triclosan show rapid inhibition of Plasmodium falciparum with greatest parasite sensitivity seen in ring-stage parasites (Waller et al., 2003). Cerulenin also targets $\beta$ ketoacyl-ACP synthases I and II (although type I FAS is also sensitive) and inhibits $P$. falciparum (Table 1) (Waller et al., 2003).

Acetyl-CoA carboxylase (ACC) is also being explored as a target for drugs in parasites. As in grasses, apicomplexans have adopted the eukaryotic ACC that has become plastid-targeted and supports the type II FAS (Harwood, 1996; Zuther et al., 1999; Jelenska et al., 2001). This chloroplast-localized eukaryotic ACC is sensitive to aryloxyphenoxypropionate herbicides (Zagnitko et al., 2001). The Toxoplasma gondii apicoplast ACC enzyme shares this sensitivity to these compounds which also inhibit parasite growth (Table 1) (Zuther et al., 1999). Plasmodium falciparum is also sensitive to these compounds (Waller et al., 2003).

\section{Isoprenoid Biosynthesis}

Isoprenoids form an extremely diverse class of compounds including sterols, ubiquinones, dolichols and prenylation moieties (Sacchettini and Poulter, 1997). All isoprenoid compounds depend on the precursor isomers isopentenyl diphosphate (IPP) and dimethylallyl diphosphate (DMAPP). There are two alternate pathways for IPP/DMAPP synthesis. Animals and fungi rely upon the mevalonate pathway, which was the first described. More recently, a mevalonate-independent pathway has been described from eubacteria and plastids proceeding via 1-deoxy-D-xylulose 5-phosphate (DOXP) instead. Plants and some algae possess both pathways, the mevalonate pathway in the cytosol and the DOXP pathway in the plastids (Lichtenthaler, 1999). Three genes for the DOXP pathway, DOXP synthase, DOXP reductoisomerase and MECDP synthase (IspF or YgbB), have recently been identified from Plasmodium falciparum and all possess bipartite presequences (Gardner et al., 1998; Jomaa et al., 1999; Gardner et al., 2002). Moreover, DOXP reductoisomerase is shown to target to apicoplasts, and the recombinant expression of this enzyme verified DOXP reductoisomerase activity which has since also been measured from $P$. falciparum extracts (Jomaa et al., 1999; Wiesner et al., 2000). This data presents a strong case for a DOXP pathway for isoprenoid synthesis in the apicoplast of $P$. falciparum. There is no evidence of genes for the mevalonate pathway in $P$. falciparum nor substantial incorporation of labeled mevalonate into isoprenoids (Mbaya et al., 1990). An apicoplast-based pathway may be the sole provider of de novo synthesized IPP/DMAPP in parasites.

Drugs that Target DOXP Isoprenoid Biosynthesis

DOXP reductoisomerase is the target of the antibiotic fosmidomycin, and both fosmidomycin and a derivative, FR-900098, show effective inhibition of Plasmodium falciparum in the nanomolar range (Table 1). Inhibition of recombinantly expressed enzyme is verified, and both compounds are very effective at parasite clearance in mouse models (Jomaa et al., 1999). Recently, modified forms of FR-900098 showed even greater potency (Reichenberg et al., 2001) making these drugs excellent candidates for further development for clinical use.

\section{Ferredoxin - A Source of Reducing Power}

A tantalizing insight into apicoplast metabolism is offered by the identification of genes for the plastid redox pair [2Fe-2S] ferredoxin (Fd) and ferredoxin-NADP+ reductase (FNR) from Plasmodium falciparum and Toxoplasma gondii respectively (Vollmer et al., 2001). FNR catalyses the reversible reaction:

$2 \mathrm{Fd}_{\text {red }}+\mathrm{NADP}^{+}+\mathrm{H}^{+} \rightarrow 2 \mathrm{Fd}_{\mathrm{ox}}+\mathrm{NADPH}$. In photosynthetic systems $\mathrm{Fd}$ accepts an electron from photosystem I and transfers it to $\mathrm{NADP}^{+}$driving the above reaction forward and producing NADPH required for Calvin cycle reactions. In the non-photosynthetic plastids of roots, this reaction is driven in the reverse direction by a structurally distinct isoform of FNR. The result is a source of reduced Fd, that provides essential reductant for plastid enzymes such as glutamate synthase, fatty acid desaturases, nitrite reductase, and sulfite reductase (Shanklin and Cahoon, 1998; Neuaus and Emes, 2000). In apicomplexans both genes encode bipartite presequences for apicoplast targeting that are processed off to form mature proteins (Vollmer et al., 2001). Recombinant expression of $P$. falciparum $\mathrm{Fd}$ confirms that this protein binds iron, and analysis of the T. gondii FNR identifies strong similarities to the root form of FNR (Vollmer et al., 2001). These proteins thus provide good circumstantial evidence for a supply of Fd-reductant in apicoplasts. While no candidate enzymes that utilize this reductant have yet been identified 
in the apicoplast, the presence of a pathway for fatty acid biosynthesis indicates that fatty acid desaturases are one likely group.

\section{Heme Biosynthesis}

Heme is an iron bound tetrapyrrole that serves as an electron carrying prosthetic group in parasite cytochromes and also appears to play a role in protein synthesis in Plasomdium falciparum (Surolia and Padmanaban, 1991). In plants, chlorophyll pigments are derived from a magnesium bound tetrapyrrole, and hence both molecules share a common biosynthetic pathway. The first committed step of tetrapyrrole synthesis is the formation of $\delta$-aminolaevulinic acid (ALA), but there are two pathways to ALA. In animals and fungi $A L A$ synthase (ALAS) uses glycine and succinyl-CoA to create ALA in the mitochondrion - the so-called Shemin pathway. An alternate pathway is found in plastids and most bacteria. This $\mathrm{C}_{5}$ or glutamate pathway generates ALA from glutamate, and is believed to be the only source of ALA in plants (Beale and Castelfranco, 1974). Euglenoid algae are unusual in that they possess both pathways, the Shemin in the mitochondrion and the $\mathrm{C}_{5}$ in the plastid (Weinstein and Beale, 1983). From ALA to tetrapyrroles the pathways are equivalent for both plants and animals and require a further seven enzymes. Curiously, in euglenoids there may only be a plastid set of these downstream enzymes (Shashidhara and Smith, 1991), suggesting that mitochondrial derived ALA may be imported to plastids for further processing.

Plasmodium falciparum is apparently unable to utilize the heme derived from erythrocyte hemoglobin and instead synthesizes its own (Surolia and Pasmanaban, 1992; Wilson et al., 1996a). Glycine is incorporated into ALA, implicating a Shemin pathway for ALA synthesis in the mitochondrion (Surolia and Pasmanaban, 1992) and indeed ALAS is found in the genome (Wilson et al., 1996a; Varadharajan et al., 2002; Gardner et al., 2002). However, from here the story becomes more complex. Remarkably the next enzyme in this pathway, ALA dehydrase (ALAD), is apparently imported into Plasmodium from the host erythrocyte cytoplasm (Bonday et al., 1997; Bonday et al., 2000; Padmanaban and Rangarajan, 2000). Yet Plasmodium spp. also encode their own ALAD. This version shares features with plant $A L A D$ including a preference for $\mathrm{Mg}^{2+}$ cofactors rather than $\mathrm{Zn}^{2+}$ used by the mitochondrial $A L A D$, and is phylogenetically closer to plant ALADs (Sato et al., 2000). Moreover, the gene encodes a bipartite presequence for apicoplast targeting (van Dooren et al., 2002). This apparent duplicity is difficult to rationalize, however at least two of the next three enzymes are represented in the genome (porpobilinogen deaminase and urophophyrinogen III decarboxylase), and these also have plastid-targeting presequences (Gardner et al., 2002). This, therefore, provides a firm case for this portion of the heme biosynthetic pathway being apicoplast localized. A final twist in this story is that the remaining three steps of heme synthesis (catalyzed by coproporphorinogen oxidase, protoporphorinogen oxidase and ferrochelatase) most likely occur in the mitochondrion (Gardner et al., 2002).
This somewhat convoluted pathway, alternating from mitochodrion to apicoplast to mitochondrion, can in fact be rationalized quite simply. An apicoplast-based segment of heme biosynthesis has taken over the part of this pathway that in animals (and most probably the apicoplast ancestor) occurs in the cytosol. This is apparently a further case where duplicated pathways have been rationalized, this time utilising elements of both. The mechanism of exchange of heme intermediates between these two organelles remains to be elucidated, however such exchange also occurs in plants and apparently euglenoid algae. A role for the imported hostderived ALAD remains to be substantiated.

\section{Conclusions}

The metabolism of the apicoplast is an unfolding story and the completion of the Plasmodium falciparum genome brings us to an extremely exciting point in this process. However, the challenge now must begin to swing towards defining the end products of apicoplast metabolic pathways if we are to understand the full significance of this organelle and any drug targets that it may hold. Presently we have good evidence for fatty acid synthesis and isoprenoid synthesis. However, it is yet to be demonstrated that any of their products are exported from the apicoplast to the rest of the cell. Fatty acids could be expected to incorporate into phospholipids, glycosylphosphati dylinositols and other acyl moieties such as on proteins. Apicoplast-derived isoprenoids may well find their way into the mitochondrion as ubiquinones, or as dolicols or isoprenyl groups on proteins and other molecules. A further interesting question is, are all apicoplasts equal? Genome data from other Plasmodium species, and other apicomplexans will be able to tell us whether all apicoplasts contain a similar suite of metabolic pathways, or whether some have been culled or refined to suit each parasite's niche. Finally, with a near complete set of apicoplast genes in our hands, the regulation of these pathways throughout the parasites life cycle can be addressed (through microarray technologies for instance) in order to shed further light on the significance of apicoplast function.

\section{Note Added in Proof}

Recent advances in apicoplast research include a detailed prediction of apicoplast metabolism in Plasmodium falciparum based on bioinformatics approaches (Ralph et al., Metabolic maps and functions of the Plasmodium falciparum apicoplast, Nature Rev. Micro. 2 (2004) 203-216), and an extensive analysis of the functional domains of an apicoplast transit peptide in Toxoplasma gondii (Harb et al., Multiple functionally redundant signals mediate targeting to the apicoplast in the apicomplexan parasite Toxoplasma gondii. Euk. Cell 3 (2004) 663674.)

\section{Acknowledgements}

RFW was supported by a NHMRC Peter Doherty Fellowship and GIM is supported by a HHMI International Scholar Grant and an ARC Professorial Fellowship. 


\section{References}

Aikawa, M. 1966. The fine structure of the erythrocytic stage of three avian malarial parasites, Plasmodium fallax, $P$. lophyrae, and $P$. cathemerium. Amer. J. Trop. Med Hyg. 15: 449-471.

Aikawa, M. 1971. Plasmodium: the fine structure of malarial parasites. Exp. Parasitol. 30: 284-320.

Aikawa, M. and Jordan, H. 1968. Fine structure of reptilian malarial parasite. J. Parasitol. 54: 1023-1033.

Araujo, F.G., Slifer, T. and Remington, J.S. 1994. Rifabutin is active in murine models of toxoplasmosis. Antimicrob. Agents Chemother. 38: 570-575.

Baldauf, S., Roger, A., Wenk-Siefert, I. and Doolittle, W. 2000. A kingdom-level phylogeny of eukaryotes based on combined protein data. Science 290: 972-977.

Bannister, L.H., Hopkins, J.M., Fowler, R.E., Krishna, S., Mitchell, G.H. 2000. A brief illustrated guide to the ultrastructure of Plasmodium falciparum asexual blood stages. Parasitol Today. 16(10): 427-433.

Beale, S. and Castelfranco, P. 1974. The biosynthesis of delta-aminolevulinic acid in higher plants. II. Formation of ${ }^{14} \mathrm{C}$-delta-aminolevulinic acid from labeled precursors in greening plant tissues. Plant Physiol. 53: 297-303.

Beckers, C.J.M., Roos, D.S., Donald, R.G.K., Luft, B.J., Schwab, J.C., Cao, Y. and Joiner, K.A. 1995. Inhibition of cytoplasmic and organellar protein synthesis in Toxoplasma gondii - implications for the target of macrolide antibiotics. J. Clin. Invest. 95: 367-376.

Beech, P.L., Nheu, T., Schultz, T., Herbert, S., Lithgow, T., Gilson, P.R. and McFadden, G.I. 2000. Mitochondrial FtsZ in a chromophyte alga. Science 287: 1276-1279.

Blanchard, J. and Hicks, J.S. 1999. The nonphotosynthetic plastid in malarial parasites and other apicomplexans is derived from outside the green plastid lineage. J. Euk. Microbiol. 46: 367-375.

Bonday, Z.Q., Dhanasekaran, S., Rangarajan, P.N. and Padmanaban, G. 2000. Import of host deltaaminolevulinate dehydratase into the malarial parasite: identification of a new drug target. Nat. Med. 6: 898903.

Bonday, Z.Q., Taketani, S., Gupta, P.D. and Padmanaban, G. 1997. Heme biosynthesis by the malarial parasite. Import of delta- aminolevulinate dehydrase from the host red cell. J. Biol. Chem. 272: 21839-21846.

Borst, P., Overdlve, J.P., Weijers, P.J., Fase-Fowler, F. and Berg, M.V.D. 1984. DNA circles with cruciforms from Isospora (Toxoplasma) gondii. Biochim. Biophys. Acta 781: 100-111.

Brown, S.B., Houghton, J.D. and Vernon, D.I. 1990. Biosynthesis of phycobilins. Formation of the chromophore of phytochrome, phycocyanin and phycoerythrin. J. Photochem. Photobiol. B 5: 3-23.

Bruce, B.D. 2001. The paradox of plastid transit peptides: conservation of function despite divergence in primary structure. Biochim. Biophys. Acta 1541: 2-21.

Budimulja, A.S., Syafruddin, Tapchaisri, P., Wilairat, P. and Marzuki, S. 1997. The sensitivity of Plasmodium protein synthesis to prokaryotic ribosomal inhibitors. Mol. Biochem. Parasitol. 84: 137-141.

Cavalier-Smith, T. 1982. The origins of plastids. Biol. J. Linn. Soc. 17: 289-306.
Cheresh, P., Harrison, T., Fujioka, H. and Haldar, K. 2002. Targeting the malarial plastid via the parasitophorous vacuole. J. Biol. Chem. 277: 16265-16277.

Cline, K. and Henry, R. 1996. Import and routing of nucleus-encoded chloroplast proteins. Ann. Rev. Cell Dev. Biol. 12: 1-26.

Clough, B., Rangachari, K., Strath, M., Preiser, P.R. and Wilson, R. 1999. Antibiotic inhibitors of organellar protein synthesis in Plasmodium falciparum. Protist 150: 189-195.

Clough, B., Strath, M., Preiser, P., Denny, P. and Wilson, R. 1997. Thiostrepton binds to malarial plastid rRNA. FEBS Lett. 406: 123-125.

Crary, J.L. and Haldar, K. 1992. Brefeldin A inhibits protein secretion and parasite maturation in the ring stage of Plasmodium falciparum. Mol Biochem Parasitol 53: 185-192.

Creasey, A., Mendis, K., Carlton, J., Williamson, D., Wilson, I. and Carter, R. 1994. Maternal inheritance of extrachromosomal DNA in malaria parasites. Mol. Biochem. Parasitol. 65: 95-98.

Deane, J.A., Fraunholz, M., Su, V., Maier, U.G., Martin, W., Durnford, D.G. and McFadden, G.I. 2000. Evidence for nucleomorph to host nucleus gene transfer: lightharvesting complex proteins from cryptomonads and chlorarachniophytes. Protist 151: 239-252.

Delwiche, C. 1999. Tracing the tread of plastid diversity through the tapestry of life. Am. Nat. 154: S164-S177.

Delwiche, C.F. and Palmer, J.D. 1997. The origin of plastids and their spread via secondary endosymbiosis. PI. Syst. Evol. [Suppl] 11: 51-86.

Denny, P., Preisser, P., Williamson, D. and Wilson, I. 1998. Evidence for a single origin of the $35 \mathrm{~kb}$ plastid DNA in apicomplexans. Protist 149: 51-59.

DeRocher, A., Feagin, J. and Parsons, M. 2001. ER to apicoplast targeting in Toxoplasma gondii. Mol. Biol. Cell 12: 382a.

DeRocher, A., Hagen, C.B., Froehlich, J.E., Feagin, J.E. and Parsons, M. 2000. Analysis of targeting sequences demonstrates that trafficking to the Toxoplasma gondii plastid branches off the secretory system. J. Cell Sci. 113: 3969-3977.

Diniz, J., Silva, E., Lainson, R. and Souza, W.d. 2000. The fine structure of Garnia gonadati and its association with the host cell. Parasitol. Res. 86: 971-977.

Divo, A., Sartorelli, A., Patton, C. and Bia, F. 1988. Activity of fluoroqinolone antibiotics against Plasmodium falciparum in vitro. Antimicrob. Agents Chemother. 32: 1182-1186.

Divo, A.A., Geary, T.G., Jensen, J.B. and Ginsburg, H. 1985. The mitochondrion of Plasmodium falciparum visualized by rhodamine 123 fluorescence. J. Protozool. 32: 442-446.

Dore, E., Frontali, C., Forte, T. and Fratarcangeli, S. 1983. Further studies and electron microscopic characterization of Plasmodium berghei DNA. Mol. Biochem. Parasitol. 8: 339-352.

Dubremetz, J.F. 1995. Toxoplasma gondii: cell biology update. In: Molecular Approaches to Parasitology. Wiley-Liss Inc. p. 345-358.

Dunn, P.P.J., Stephens, P.J. and Shirley, M.W. 1998. Eimeria tenella - two species of extrachromosomal 
DNA revealed by pulsed-field gel electrophoresis. Parasitol. Res. 84: 272-275.

Egea, N. and Lang-Unnasch, N. 1995. Phylogeny of the large extrachromosomal DNA of organisms in the phylum Apicomplexa. J. Euk. Microbiol. 42: 679-684.

Ellis, K.E., Clough, B., Saldanha, J.W. and Wilson, R.J. 2001. Nifs and Sufs in malaria. Mol. Microbiol. 41: 973981.

Emanuelsson, O., Nielsen, H. and von Heijne, G. 1999. ChloroP, a neural network-based method for predicting chloroplast transit peptides and their cleavage sites. Protein Sci. 8: 978-984.

Fagan, T., Hastings, J. and Morse, D. 1998. Glyceraldehyde-3-phosphate dehydrogenase phylogeny supports and independent origin of the dinoflagellate chloroplast. Endocyt. Cell Res. 13 (supplement): 33.

Fast, N.M., Kissinger, J.C., Roos, D.S. and Keeling, P.J. 2001. Nuclear-encoded, plastid-targeted genes suggest a single common origin for apicomplexan and dinoflagellate plastids. Mol. Biol. Evol. 18: 418-426.

Feagin, J.E. and Drew, M.E. 1995. Plasmodium falciparum: alterations in organelle transcript abundance during the erythrocytic cycle. Exp. Parasitol. 80: 430-440.

Fichera, M.E., Bhopale, M.K. and Roos, D.S. 1995. In vitro assays elucidate peculiar kinetics of clindamycin action against Toxoplasma gondii. Antimicrob. Agents Chemother. 39: 1530-1537.

Fichera, M.E. and Roos, D.S. 1997. A plastid organelle as a drug target in apicomplexan parasites. Nature 390: 407-409.

Fish, W.R. 1995. Lipid and membrane metabolism of the malaria parasite and the African trypanosome. In: Biochemistry and Molecular Biology of Parasites. Marr, J.J. and Müller, M. eds. Academic Press, London. p. 133-145.

Foley, M. and Tilley, L. 1998. Protein trafficking in malariainfected erythrocytes. Int. J. Parasitol. 28: 1671-1680.

Foth, B.J., Ralph, S.A., Tonkin, C.J., Struck, N.S., Fraunholz, M., Roos, D.S. Cowman, A.F. and McFadden, G.I. (2003) Dissection apicoplast targeting in the malaria parasite Plasmodium falciparum. Science 299: 705-708.

Gardner, M.J., Feagin, J.E., Moore, D.J., Spencer, D.F., Gray, M.W., Williamson, D.H. and Wilson, R.J. 1991. Organization and expression of small subunit ribosomal RNA genes encoded by a 35-kilobase circular DNA in Plasmodium falciparum. Mol. Biochem. Parasitol. 48: 77-88.

Gardner, M.J., Goldman, N., Barnett, P., Moore, P.W., Rangachari, K., Strath, M., Whyte, A., Williamson, D.H. and Wilson, R.J. 1994. Phylogenetic analysis of the rpoB gene from the plastid-like DNA of Plasmodium falciparum. Mol. Biochem. Parasitol. 66: 221-231.

Gardner, M.J., Tettelin, H., Carucci, D.J., Cummings, L.M., Aravind, L., Koonin, E.V., Shallom, S., Mason, T., Yu, K., Fujii, C., Pederson, J., Shen, K., Jing, J.P., Aston, C., Lai, Z.W., Schwartz, D.C., Pertea, M., Salzberg, S., Zhou, L.X., Sutton, G.G., Clayton, R., White, O., Smith, H.O., Fraser, C.M., Adams, M.D., Hoffman, S.L. 1998. Chromosome 2 sequence of the human malaria parasite Plasmodium falciparum. Science 282: 11261132.
Gardner, M.J., Hall, N., Fung, E., White, O., Berriman, M., Hyman, R.W., Carlton, J.M., Pain, A., Nelson, K.E., Bowman, S., Paulsen, I.T., James, K., Eisen, J.A., Rutherford, K., Salzberg, S.L., Craig, A., Kyes, S., Chan, M.S., Nene, V., Shallom, S.J., Suh, B., Peterson, J., Angiuoli, S., Pertea, M., Allen, J., Selengut, J., Haft, D., Mather, M.W., Vaidya, A.B., Martin, D.M., Fairlamb, A.H., Fraunholz, M.J., Roos, D.S., Ralph, S.A., McFadden, G.I., Cummings, L.M., Subramanian, G.M., Mungall, C., Venter, J.C., Carucci, D.J., Hoffman, S.L., Newbold, C., Davis, R.W., Fraser, C.M. and Barrell, B. 2002. Genome sequence of the human malaria parasite Plasmodium falciparum. Nature 2002 419: 498-511

Gilson, P.R. and Beech, P.L. 2001. Cell division protein FtsZ: running rings around bacteria, chloroplasts and mitochondria. Res. Microbiol. 152: 3-10.

Gleeson, M.T. 2000. The plastid in Apicomplexa: what use is it? Int. J. Parasitol. 30: 1053-1070.

Gozalbes, R., Brun-Pascaud, M., Garcia-Domenech, R., Galvez, J., Girard, P.M., Doucet, J.P. and Derouin, F. 2000. Anti-Toxoplasma activities of 24 quinolones and fluoroquinolones in vitro: Prediction of activity by molecular topology and virtual computational techniques. Antimicrob. Agents Chemother. 44: 27712776.

Gray, M.W. and Lang, B.F. 1998. Transcription in chloroplasts and mitochondria: a tale of two polymerases. Trends Microbiol. 6: 1-3.

Harwood, J. 1996. Recent advances in the biosynthesis of plant fatty-acids. Biochim. Biophys. Acta. 1301: 7-56.

Hayashi, M., Taniguchi, S., Ishizuka, Y., Kim, H.S., Wataya, Y., Yamamoto, A. and Moriyama, Y. 2001. A homologue of $\mathrm{N}$-ethylmaleimide-sensitive factor in the malaria parasite Plasmodium falciparum is exported and localized in vesicular structures in the cytoplasm of infected erythrocytes in the brefeldin A-sensitive pathway. J. Biol. Chem. 276: 15249-15255.

He, C.Y., Shaw, M.K., Pletcher, C.H., Striepen, B., Tilney, L.G. and Roos, D.S. 2001. A plastid segregation defect in the protozoan parasite Toxoplasma gondii. EMBO J. 20: 330-339.

Holz, G.G. 1977. Lipids and the malarial parasite. Bull. WHO 55: 237-248.

Hopkins, J., Fowler, R., Krishna, S., Wilson, I., Mitchell, G. and Bannister, L. 1999. The plastid in Plasmodium falciparum asexual blood stages: a three-dimensional ultrastructural analysis. Protist 150: 283-295.

Howe, C.J. 1992. Plastid origin of an extrachromosomal DNA molecule from Plasmodium, the causative agent of malaria. J. Theor. Biol. 158: 199-205.

Ivey, R.A., 3rd, Subramanian, C. and Bruce, B.D. 2000. Identification of a Hsp70 recognition domain within the rubisco small subunit transit peptide. Plant Physiol. 122: 1289-1299.

Jackson-Constan, D., Akita, M. and Keegstra, K. 2001. Molecular chaperones involved in chloroplast protein import. Biochim. Biophys. Acta 1541: 102-113.

Jarvis, P. and Soll, J. 2001. Toc, Tic, and chloroplast protein import. Biochim. Biophys. Acta 1541: 64-79.

Jeffries, A.C. and Johnson, A.M. 1996. The growing importance of the plastid-like DNAs of the Apicomplexa. Int. J. Parasitol. 26: 1139-1150. 
Jelenska, J., Crawford, M.J., Harb, O.S., Zuther, E., Haselkorn, R., Roos, D.S. and Gornicki, P. 2001. Subcellular localization of acetyl-CoA carboxylase in the apicomplexan parasite Toxoplasma gondii. Proc. Natl. Acad. Sci. USA 98: 2723-2728.

Jomaa, H., Wiesner, J., Sanderbrand, S., Altincicek, B., Weidemeyer, C., Hintz, M., Turbachova, I., Eberl, M., Zeidler, J., Lichtenthaler, H.K., Soldati, D. and Beck, E. 1999. Inhibitors of the nonmevalonate pathway of isoprenoid biosynthesis as antimalarial drugs. Science 285: 1573-1576.

Keeling, P.J., Palmer, J.D., Donald, R.G.K., Roos, D.S., Waller, R.F. and McFadden, G.I. 1998. Shikimate pathway in apicomplexan parasites. Nature 397: 219220.

Khan, A.A., Slifer, T., Araujo, F.G. and Remington, J.S. 1996. Trovafloxacin is active against Toxoplasma gondii. Antimicrob. Agents Chemother. 40: 1855-1859.

Kilejian, A. 1975. Circular mitochondrial DNA from the avian malarial parasite Plasmodium lophurae. Biochim. Biophys. Acta 390: 276-284.

Kohler, R., Cao, J., Zipfel, W., Webb, W. and Hanson, M. 1997. Exchange of protein molecules through connections between higher plant plastids. Science 276: 2039-2042

Köhler, S., Delwiche, C.F., Denny, P.W., Tilney, L.G., Webster, P., Wilson, R.J.M., Palmer, J.D. and Roos, D.S. 1997. A plastid of probable green algal origin in apicomplexan parasites. Science 275: 1485-1488.

Kroth, P. and Strotmann, H. 1999. Diatom plastids: Secondary endocytobiosis, plastid genome and protein import. Physiologia Plantarum 107: 136-141.

Kudo, R. 1971. Protozoology. Charles C Thomas, Springfield, Illinois.

Lang-Unnasch, N., Reith, M., Munholland, J. and Barta, J. 1998. Plastids are widespread and ancient in parasites of the phylum Apicomplexa. J. Int. Parasitol. 28: 17431754.

Law, A.E., Mullineaux, C.W., Hirst, E.M., Saldanha, J. and Wilson, R.J. 2000. Bacterial orthologues indicate the malarial plastid gene ycf24 is essential. Protist 151: 317-327.

Li, J.N., Maga, J.A., Cermakian, N., Cedergren, R. and Feagin, J.E. 2001. Identification and characterization of a Plasmodium falciparum RNA polymerase gene with similarity to mitochondrial RNA polymerases. Mol. Biochem. Parasitol. 113: 261-269.

Liaud, M.-F., Brandt, U., Scherzinger, M. and Cerff, R. 1997. Evolutionary origin of cryptomonad microalgae: two novel chloroplast/cytosol-specific GAPDH genes as potential markers of ancestral endosymbiont and host cell components. J. Mol. Evol. 44 Suppl. 1: S28-37.

Lichtenthaler, H.K. 1999. The 1-deoxy-D-xylulose-5phosphate pathway of isoprenoid biosynthesis in plants [Review]. Ann. Rev. Plant Physiol. Plant Mol. Biol. 50: 47-65.

Martin, W. and Herrmann, R.G. 1998. Gene transfer from organelles to the nucleus: how much, what happens, and why? Plant Physiol. 118: 9-17.

Matsuzaki, M., Kikuchi, T., Kita, K., Kojima, S. and Kuroiwa, T. 2001. Large amounts of apicoplast nucleoid DNA and its segregation in Toxoplasma gondii. Protoplasma 218: 180-191.
Mbaya, B., Rigomier, D., Edorh, G.G., Karst, F. and Schrevel, J. 1990. Isoprenoid metabolism in Plasmodium falciparum during the intraerythrocytic phase of malaria. Biochem. Biophys. Res. Commun. 173: 849-854.

McConkey, G.A., Rogers, M.J. and McCutchan, T.F. 1997. Inhibition of Plasmodium falciparum protein synthesis: targeting the plastid-like organelle with thiostrepton. J. Biol. Chem. 272: 2046-2049.

McFadden, G.I., Reith, M., Munholland, J. and LangUnnasch, N. 1996. Plastid in human parasites. Nature 381: 482

McFadden, G.I. and Roos, D.S. 1999. Apicomplexan plastids as drug targets. Trends Microbiol. 6: 328-333.

McFadden, G.I. and Waller, R.F. 1997. Plastids in parasites of humans. BioEssays 19: 1033-1040.

McFadden, G.I., Waller, R.F., Reith, M., Munholland, J. and Lang-Unnasch, N. 1997. Plastids in apicomplexan parasites. PI. Syst. Evol. [Suppl.] 11: 261-287.

McLeod, R., Muench, S.P., Rafferty, J.B., Kyle, D.E., Mui, E.J., Kirisits, M.J., Mack, D.G., Roberts, C.W., Samuel, B.U., Lyons, R.E., Dorris, M., Milhous, W.K. and Rice, D.W. 2001. Triclosan inhibits the growth of Plasmodium falciparum and Toxoplasma gondii by inhibition of apicomplexan Fabl. Int. J. Parasitol. 31: 109-113.

Neuhaus, H.E., and Emes, M.J. 2000. Nonphotosynthetic metabolism in plastids. Annu. Rev. Plant Physiol. and Plant Mol. Biol. 51: 111-140.

Olliaro, P., Gorini, G., Jabes, D., Regazzetti, A., Rossi, R., Marchetti, A., Tinelli, C. and Della Bruna, C. 1994. Invitro and in-vivo activity of rifabutin against Toxoplasma gondii. J. Antimicrob. Chemother. 34: 649-657.

Osteryoung, K.W. 2001. Organelle fission in eukaryotes. Curr. Opin. Microbiol. 4: 639-646.

Padmanaban, G. and Rangarajan, P.N. 2000. Heme metabolism of Plasmodium is a major antimalarial target. Biochem. Biophys. Res. Commun. 268: 665668

Peeters, N. and Small, I. 2001. Dual targeting to mitochondria and chloroplasts. Biochim. Biophys. Acta. 1541: 54-63.

Perozzo, R., Kuo, M., bir Singh Sidhu, A., Valiyaveettil, J.T., Bittman, R., Jacobs, W.R., Jr., Fidock, D.A. and Sacchettini, J.C. 2002. Structural elucidation of the specificity of the antibacterial agent triclosan for malarial enoyl ACP reductase. J. Biol. Chem. 277: 13106-13114.

Pfefferkorn, E.R. and Borotz, S.E. 1994. Comparison of mutants of Toxoplasma gondii selected for resistance to azithromycin, spiramycin, or clindamycin. Antimicrob. Agents Chemother. 338: 31-37.

Pradines, B., Spiegel, A., Rogier, C., Tall, A., Mosnier, J., Fusai, T., Trape, J.F. and Parzy, D. 2000. Antibiotics for prophylaxis of Plasmodium falciparum infections: in vitro activity of doxycycline against Senegalese isolates. Am. J. Trop. Med. Hyg. 62: 82-85.

Prigge, S.T., He, X., Gerena, L., Waters, N.C. and Reynolds, K.A. 2003. The initiating steps of a type II fatty acid synthase in Plasmodium falciparum are catalyzed by pfacp, pfmcat, and pfKASIII. Biochemistry 42: $1160-1169$. 
Pukrittayakamee, S., Viravan, C., Charoenlarp, P., Yeamput, C., Wilson, R.J. and White, N.J. 1994. Antimalarial effects of rifampin in Plasmodium vivax malaria. Antimicrob. Agents Chemother. 38: 511-514.

Ralph, S.A., D'Ombrain, M.C. and McFadden, G.I. 2001. The apicoplast as an antimalarial drug target. Drug Resist. Updat. 4: 145-151.

Read, M., Sherwin, T., Holloway, S., Gull, K. and Hyde, J. 1993. Microtubular organization visualized by immunofluorescence microscopy during erythrocytic schizogony in Plasmodium falciparum and investigation of post-translational modifications of parasite tubulin. Parasitology 106: 223-232.

Reichenberg, A., Wiesner, J., Weidemeyer, C., Dreiseidler, E., Sanderbrand, S., Altincicek, B., Beck, E., Schlitzer, M. and Jomaa, H. 2001. Diaryl ester prodrugs of FR900098 with improved in vivo antimalarial activity. Bioorg. Med. Chem. Lett. 11: 833-835.

Richter, S. and Lamppa, G.K. 1999. Stromal processing peptidase binds transit peptides and initiates their ATP. dependent turnover in chloroplasts. J. Cell Biol. 147: 33-43.

Rogers, M.J., Burkham, Y.V., McCutchan, T.F. and Draper, D.E. 1997. Interaction of thiostrepton with an RNA fragment derived from the plastid-encoded ribosomal RNA of the malaria parasite. RNA 3: 815-820.

Rogers, M.J., Cundliffe, E. and McCutchan, T.F. 1998. The antibiotic micrococcin is a potent inhibitor of growth and protein synthesis in the malaria parasite. Antimicrob. Agents Chemoth. 42: 715-716.

Roos, D.S., Crawford, M.J., Donald, R.G.K., Kissinger, J.C., Klimczak, L.J. and Striepen, B. 1999. Origin, targeting, and function of the apicomplexan plastid. Curr. Opin. Microbiol. 2: 426-432.

Roy, A., Cox, R.A., Williamson, D.H. and Wilson, R.J. 1999. Protein synthesis in the plastid of Plasmodium falciparum. Protist 150: 183-188.

Sacchettini, J.C. and Poulter, C.D. 1997. Creating isoprenoid diversity. Science 277: 1788-1789.

Sato, S., Tews, I. and Wilson, R.J.M. 2000. Impact of a plastid-bearing endocytobiont on apicomplexan genomes. Int. J. Parasitol. 30: 427-439.

Schrevel, J. 1971. Contribution a l'étude des Selenidiidae parasites d'annélides polychétes II. ultrastructure de quelques trophozoïtes. Protistologica 7: 101-130.

Shanklin, J., and Cahoon, E.B. 1998. Desaturation and related modifications of fatty acids. Annu. Rev. Plant Physiol. Plant Mol. Biol. 49: 611-641

Shashidhara, L.S. and Smith, A.G. 1991. Expression and subcellular location of the tetrapyrrole synthesis enzyme porphobilinogen deaminase in light-grown Euglena gracilis and three nonchlorophyllous cell lines. Proc. Natl. Acad. Sci. USA 88: 63-67.

Smith, S. 1994. The animal fatty acid synthase: one gene, one polypeptide, seven enzymes. FASEB J. 8: 12481259.

Speer, C.A. and Dubey, J.P. 1999. Ultrastructure of schizonts and merozoites of Sarcocystis falcatula in the lungs of budgerigars (Melopsittacus undulatus). J. Parasitol. 85: 630-637.

Strath, M., Scott, F.T., Gardner, M., Williamson, D. and Wilson, I. 1993. Antimalarial activity of rifampicin in vitro and in rodent models. Trans. R. Soc. Trop. Med. Hyg. 87: 211-216.

Striepen, B., Crawford, M.J., Shaw, M.K., Tilney, L.G., Seeber, F. and Roos, D.S. 2000. The plastid of Toxoplasma gondii is divided by association with the centrosomes. J. Cell Biol. 151: 1423-1434.

Sulli, C., Fang, Z.W., Muchal, U. and Schwartzbach, S.D. 1999. Topology of Euglena chloroplast protein precursors within the endoplasmic reticulum to Golgi to chloroplast transport vesicles. J. Biol. Chem. 274: 457-463.

Sullivan, M., Li, J., Kumar, S., Rogers, M.J. and McCutchan, T.F. 2000. Effects of interruption of apicoplast function on malaria infection, development, and transmission. Mol. Biochem. Parasitol. 109: 17-23.

Surolia, N. and Padmanaban, G. 1991. Chloroquine inhibits heme-dependent protein synthesis in Plasmodium falciparum. Proc. Natl. Acad. Sci. USA 88: 4786-4790.

Surolia, N. and Pasmanaban, G. 1992. De novo biosynthesis of heme offers a new chemotherapeutic target in the human malarial parasite. Biochem. Biophys. Res. Com. 187: 744-750.

Surolia, N. and Surolia, A. 2001. Triclosan offers protection against blood stages of malaria by inhibiting enoyl-ACP reductase of Plasmodium falciparum. Nat. Med. 7: 167-173.

Takishita, K. and Uchida, A. 1999. Molecular cloning and nucleotide sequence analysis of $p s b A$ from dinoflagellates: origin of the dinoflagellate plastid. Phycol. Res. 47: 207-216.

The Arabidopsis Genome Initiative. 2000. Analysis of the genome sequence of the flowering plant Arabidopsis thaliana. Nature 408: 796-815.

Varadharajan S., Dhanasekaran S., Bonday Z.Q., Rangarajan P.N., Padmanaban G. 2002. Involvement of delta-aminolaevulinate synthase encoded by the parasite gene in de novo haem synthesis by Plasmodium falciparum. Biochem J. 367: 321-327.

Van de Peer, Y., Baldauf, S., Doolittle, W. and Meyer, A. 2000. An updated and comprehensive rRNA phylogeny of (crown) eukaryotes based on rate-calibrated evolutionary distances. J. Mol. Evol. 51: 565-576.

van Dooren, G.G., Schwartzbach, S.D., Osafune, T. and McFadden, G.I. 2001. Translocation of proteins across the multiple membranes of complex plastids. Biochim. Biophys. Acta 1541: 34-53.

van Dooren, G.G., Su, V., D'Ombrain, M.C. and McFadden, G.I. 2002. Processing of an apicoplast leader sequence in Plasmodium falciparum and the identification of a putative leader cleavage enzyme. J. Biol. Chem. 277: 23612-23619.

Van Wye, J., Ghori, N., Webster, P., Mitschler, R.R., Elmendorf, H.G. and Haldar, K. 1996. Identification and localization of rab6, separation of rab6 from ERD2 and implications for an 'unstacked' Golgi, in Plasmodium falciparum. Mol. Biochem. Parasitol. 83: 107-120.

Vial, G.J. and Ancelin, M.L. 1992. Malarial lipids. An overview. Subcell. Biochem. 18: 259-306.

Vivier, E. and Desportes, I. 1990. Apicomplexa. In: Handbook of Protoctista. Margulis, L., Corliss, J.O., Melkonian, M. and Chapman, D.J. eds., Jones and Bartlett Publishers, Boston. p. 549-573. 
Vivier, E., Petitprez, A. and Landau, I. 1972. Observations ultrastructurales sur la sporoblastogenése de l'hémogregarine, Hepatozoon domerguei, Coccide Adeleidea. Protistologica 8: 315-334.

Viviere, E. and Hennere, E. 1965. Ultrastrcture des stades végétatifs de la coccidie Coelotropha durchoni. Protistologica 1: 89-104.

Vollmer, M., Thomsen, N., Wiek, S. and Seeber, F. 2001. Apicomplexan Parasites Possess Distinct Nuclear-encoded, but Apicoplast-localized, Plant-type Ferredoxin-NADP+ Reductase and Ferredoxin. J. Biol. Chem. 276: 5483-5490.

Waegemann, K. and Soll, J. 1996. Phosphorylation of the transit sequence of chloroplast precursor proteins. J. Biol. Chem. 271: 6545-6554.

Waller, R.F., Keeling, P.J., Donald, R.G.K., Striepen, B., Handman, E., Lang-Unnasch, N., Cowman, A.F., Besra, G.S., Roos, D.S. and McFadden, G.I. 1998. Nuclearencoded proteins target to the plastid in Toxoplasma gondii and Plasmodium falciparum. Proc. Natl. Acad. Sci. U.S.A. 95: 12352-12357.

Waller, R.F., Reed, M.B., Cowman, A.F. and McFadden, G.I. 2000. Protein trafficking to the plastid of Plasmodium falciparum is via the secretory pathway. EMBO J. 19: 1794-1802.

Waller, R.F., Ralph, S.A., Reed, M.B., Su, V., Douglas, J.D., Minnikin, D.E., Cowman, A.F., Besra, G.S. and McFadden G.I. 2003. A type II pathway for fatty acid biosynthesis presents drug targets in Plasmodium falciparum. Atntimicrob. Agents Chemother. 47: 297301.

Waters, C.T. and Janse, C.J. 2004. Malaria Parasites: Genomes and Molecular Biology (Wymondham: Caister Academic Press).

Waters, N.C., Kopydlowski, K.M., Guszcznski, T., Wei, L., Sellers, P., Ferlan, J.T., Lee, P.J., Li, Z., Woodard, C.L., Shallom, S., Gardner, M.J. and Prigge, S.T. 2002. Functional characterization of the acyl carrier protein (PfACP) and beta-ketoacyl ACP synthase II (PfKASIII) from Plasmodium falciparum. Mol. Biochem. Parasitol. 123: 85-94.

Weinstein, J.D. and Beale, S.I. 1983. Separate physiological roles and subcellular compartments for two tetrapyrrole biosynthetic pathways in Euglena gracilis. J. Biol. Chem. 258: 6799-6807.

Weissig, V., Vetro-Widenhouse, T. and Rowe, T. 1997. Topoisomerase II inhibitors induce cleavage of nuclear and $35-\mathrm{kb}$ plastid DNAs in the malarial parasite Plasmodium falciparum. DNA Cell Biol. 16: 1483-1492.

Wickham, M.E., Rug, M., Ralph, S.A., Klonis, N., McFadden, G.I., Tilley, L. and Cowman, A.F. 2001. Trafficking and assembly of the cytoadherence complex in Plasmodium falciparum-infected human erythrocytes. EMBO J. 20: 5636-5649.

Wiesner, J., Hintz, M., Altincicek, B., Sanderbrand, S., Weidemeyer, C., Beck, E. and Jomaa, H. 2000. Plasmodium falciparum: Detection of the Deoxyxylulose 5-Phosphate Reductoisomerase Activity. Exp. Parasitol. 96: 182-186.

Williamson, D.H., Denny, P.W., Moore, P.W., Sato, S., McCready, S. and Wilson, R.J. 2001. The in vivo conformation of the plastid DNA of Toxoplasma gondii: implications for replication. J. Mol. Biol. 306: 159-168.
Wilson, C.M., Smith, A.B. and Baylon, R.V. 1996a. Characterization of the delta-aminolevulinate synthase gene homologue in $P$. falciparum. Mol. Biochem. Parasitol. 75: 271-276.

Wilson, R.J., Fry, M., Gardner, M.J., Feagin, J.E. and Williamson, D.H. 1992. Subcellular fractionation of the two organelle DNAs of malaria parasites. Curr. Genet. 21: 405-408.

Wilson, R.J.M., Denny, P.W., Preiser, P.R., Rangachari, K., Roberts, K., Roy, A., Whyte, A., Strath, M., Moore, D.J., Moore, P.W. and Williamson, D.H. 1996b. Complete gene map of the plastid-like DNA of the malaria parasite Plasmodium falciparum. J. Mol. Biol. 261: 155-172.

Wilson, R. J. M., Gardner, M. J., Feagin, J. E. and Williamson, D. H. 1991. Have malaria parasites three genomes? Parasitol. Today 7: 134-136.

Wilson, R.J.M. and Williamson, D.H. 1997. Extrachromosomal DNA in the Apicomplexa. Microbiol. Mol. Biol. Rev. 61: 1-16.

Woods, K.M., Nesterenko, M.V. and Upton, S.J. 1996. Efficacy of 101 antimicrobials and other agents on the development of Cryptosporidium parvum in vitro. Ann. Trop. Med. Parasitol. 90: 603-615.

Yung, S. and Lang-Unnasch, N. 1999. Targeting of a nuclear encoded protein to the apicoplast of Toxoplasma gondii. J. Euk. Microbiol. 46: 79S-80S.

Yung, S., Unnasch, T.R. and Lang-Unnasch, N. 2001. Analysis of apicoplast targeting and transit peptide processing in Toxoplasma gondii by deletional and insertional mutagenesis. Mol. Biochem. Parasitol. 118: 11-21.

Zagnitko, O., Jelenska, J., Tevzadze, G., Haselkorn, R. and Gornicki, P. 2001. An isoleucine/leucine residue in the carboxyltransferase domain of acetyl-CoA carboxylase is critical for interaction with aryloxyphenoxypropionate and cyclohexanedione inhibitors. Proc. Natl. Acad. Sci. USA 98: 6617-6622.

Zhang, Z., Cavalier-Smith, T. and Green, B. 2001. A family of selfish minicircular chromosomes with jumbled chloroplast gene fragments from a dinoflagellate. Mol. Biol. Evol. 18: 1558-1565.

Zhang, Z., Green, B. and Cavalier-Smith, T. 1999. Single gene circles in dinoflagellate chloroplast genomes. Nature 400: 155-159.

Zhu, G., Marchewka, M.J. and Keithly, J.S. 2000a. Cryptosporidium parvum appears to lack a plastid genome. Microbiology-Uk 146: 315-321.

Zhu, G., Marchewka, M.J., Woods, K.M., Upton, S.J. and Keithly, J.S. 2000b. Molecular analysis of a Type I fatty acid synthase in Cryptosporidium parvum. Mol. Biochem. Parasitol. 105: 253-260.

Zuegge, J., Ralph, S., Schmuker, M., McFadden, G.I. and Schneider, G. 2001. Deciphering apicoplast targeting signals - feature extraction from nuclear-encoded precursors of Plasmodium falciparum apicoplast proteins. Gene 280: 19-26.

Zuther, E., Johnson, J.J., Haselkorn, R., McLeod, R. and Gornicki, P. 1999. Growth of Toxoplasma gondii is inhibited by aryloxyphenoxypropionate herbicides targeting acetyl-CoA carboxylase. Proc. Natl. Acad. Sci. USA 96: 13387-13392. 


\section{Further Reading}

Caister Academic Press is a leading academic publisher of advanced texts in microbiology, molecular biology and medical research. Full details of all our publications at caister.com

- MALDI-TOF Mass Spectrometry in Microbiology Edited by: M Kostrzewa, S Schubert (2016) www.caister.com/malditof

- Aspergillus and Penicillium in the Post-genomic Era Edited by: RP Vries, IB Gelber, MR Andersen (2016) www.caister.com/aspergillus2

- The Bacteriocins: Current Knowledge and Future Prospects Edited by: RL Dorit, SM Roy, MA Riley (2016)

www.caister.com/bacteriocins

- Omics in Plant Disease Resistance Edited by: V Bhadauria (2016) www.caister.com/opd

- Acidophiles: Life in Extremely Acidic Environments Edited by: R Quatrini, DB Johnson (2016) www.caister.com/acidophiles

- Climate Change and Microbial Ecology: Current Research and Future Trend

Edited by: J Marxsen (2016)

www.caister.com/climate

- Biofilms in Bioremediation: Current Research and Emerging Technologies

Edited by: G Lear (2016)

www.caister.com/biorem

- Microalgae: Current Research and Applications Edited by: MN Tsaloglou (2016) www.caister.com/microalgae

- Gas Plasma Sterilization in Microbiology: Theory, Applications, Pitfalls and New Perspectives Edited by: H Shintani, A Sakudo (2016) www.caister.com/gasplasma

- Virus Evolution: Current Research and Future Directions Edited by: SC Weaver, M Denison, M Roossinck, et al. (2016) www.caister.com/virusevol

- Arboviruses: Molecular Biology, Evolution and Control Edited by: N Vasilakis, DJ Gubler (2016) www.caister.com/arbo

- Shigella: Molecular and Cellular Biology Edited by: WD Picking, WL Picking (2016) www.caister.com/shigella

-Aquatic Biofilms: Ecology, Water Quality and Wastewater Treatment

Edited by: AM Romaní, H Guasch, MD Balaguer (2016)

www.caister.com/aquaticbiofilms

- Alphaviruses: Current Biology

Edited by: S Mahalingam, L Herrero, B Herring (2016)

www.caister.com/alpha

- Thermophilic Microorganisms

Edited by: F Li (2015)

www.caister.com/thermophile
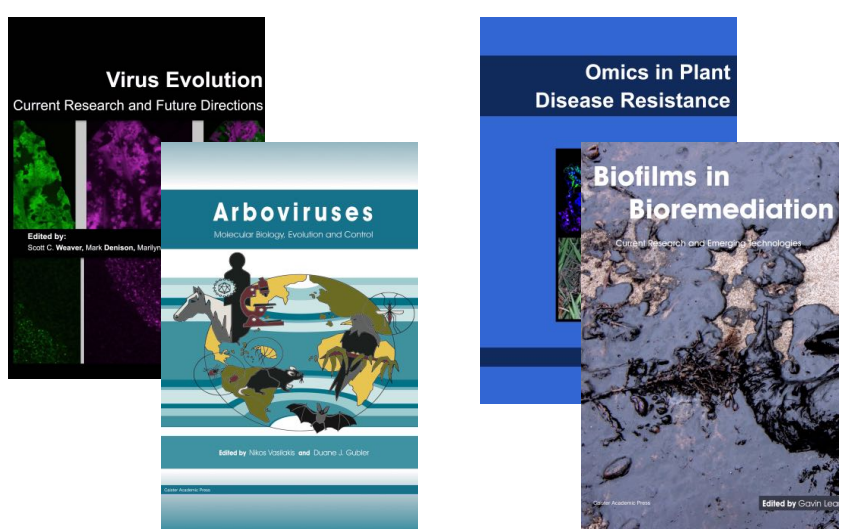
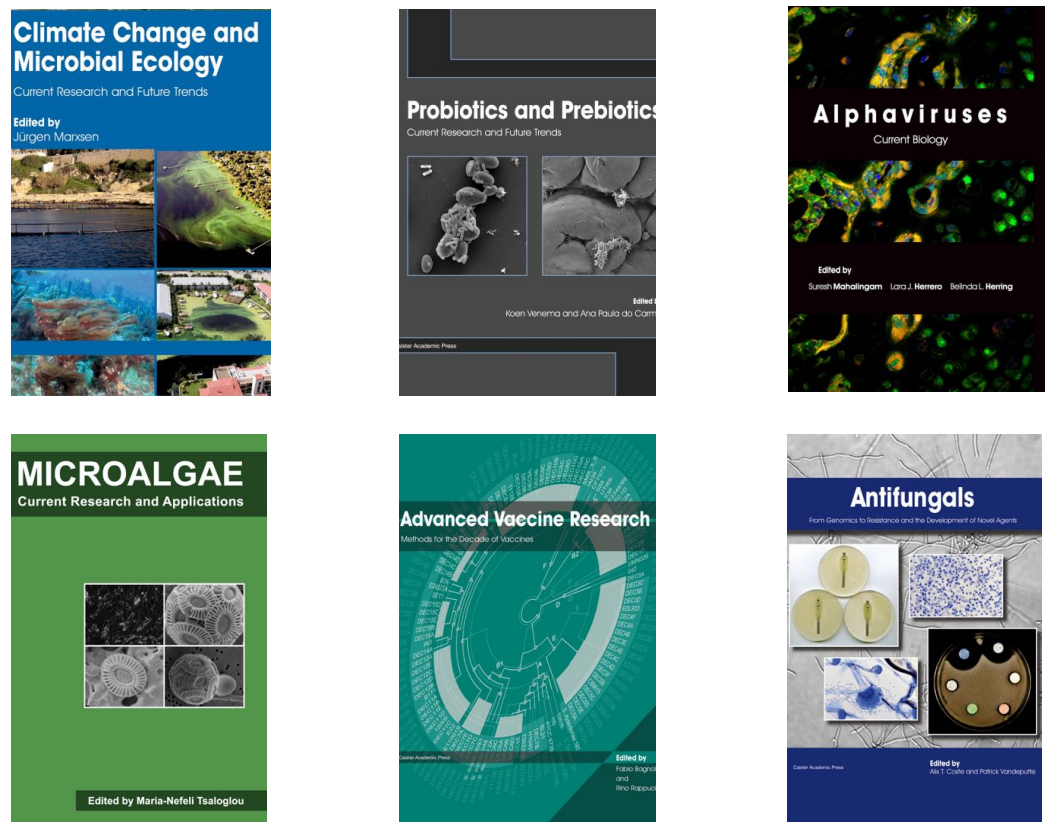

- Flow Cytometry in Microbiology: Technology and Applications Edited by: MG Wilkinson (2015) www.caister.com/flow

- Probiotics and Prebiotics: Current Research and Future Trends Edited by: K Venema, AP Carmo (2015) www.caister.com/probiotics

- Epigenetics: Current Research and Emerging Trends Edited by: BP Chadwick (2015) www.caister.com/epigenetics2015

- Corynebacterium glutamicum: From Systems Biology to Biotechnological Applications

Edited by: A Burkovski (2015)

www.caister.com/cory2

- Advanced Vaccine Research Methods for the Decade of Vaccines

Edited by: F Bagnoli, R Rappuoli (2015)

www.caister.com/vaccines

- Antifungals: From Genomics to Resistance and the Development of Novel Agents

Edited by: AT Coste, P Vandeputte (2015)

www.caister.com/antifungals

- Bacteria-Plant Interactions: Advanced Research and Future Trends Edited by: J Murillo, BA Vinatzer, RW Jackson, et al. (2015) www.caister.com/bacteria-plant

\section{- Aeromonas}

Edited by: J Graf (2015)

www.caister.com/aeromonas

- Antibiotics: Current Innovations and Future Trends

Edited by: S Sánchez, AL Demain (2015)

www.caister.com/antibiotics

- Leishmania: Current Biology and Contro Edited by: S Adak, R Datta (2015) www.caister.com/leish2

- Acanthamoeba: Biology and Pathogenesis (2nd edition) Author: NA Khan (2015)

www.caister.com/acanthamoeba2

- Microarrays: Current Technology, Innovations and Applications Edited by: Z He (2014)

www.caister.com/microarrays2

- Metagenomics of the Microbial Nitrogen Cycle: Theory, Methods and Applications

Edited by: D Marco (2014)

www.caister.com/n2 